\title{
BIBLIOGRAFÍA SOBRE TEMAS ÁRABES DEL SHARQ AL-ANDALUS (LEVANTE DE AL-ANDALUS) APÉNDICE VI
}

Por

FRANCISCO FRANCO SÁNCHEZ

MÍKEL DE EPALZA

Ofrecemos una nueva actualizacion de las Bibliografias que sobre tema árabe se han publicado anteriormente en esta misma sección Bibliografica de la Revista. Por haber salido casi juntos los anteriores números 5 y 6 , preferimos concentrar este apartado en la primera de ellas, explicando este hecho la no inclusión de estos Apéndices Bibliograficos en el número anterior.

Incluimos al final unos indices de materias y topónimos y onomástico que esperamos faciliten el repaso general y la búsqueda concreta. Hemos decidido posponer la publicación de los indices de los cinco primeros Apendices Bibliograficos, para poder dedicar un mayor tiempo y ciudado a su elaboración.

4087 - ABADIA DONAQUE, José Carlosı "Calatayud, Alfonso el Batallador y los almoravides", Papeles Bilbilitanos. Actas del Segundo Bncuentro de Bstudios Bilbilitanos, Zaragoza, ed. Centro de Est. Bllbilitanos/Inst. Fernando Catolico, vol. II, 1989, pp. 191-208.

4088 - ABADIA IRACHE, Alejandro: "Los Zauzala: una familia de moriscos aragoneses", Destiercos Aragoneses. I. Judios y Moriscos (2" Parte: La expulsión de los Moriscos), Zaragoza, ed. Instución Fernando el Católico, 1988, pp. 331-340.

4089 - ABELLAN PEREZ, Juan: "Algunos aspectos socio-econónicos de Albox a través de su libro de Apeo", Roel Cuadernos de Civilización de la Cuenca del Almanzora, Albox, 1980, pp. 43-57. Repobladores cristianos, sobre todo de origen valenciano, alicantino y murciano.

4090 - ABELLAN PEREZ, Juan: Colecaión de Documentos para la Historia del Reino de Murcia. XVI. Documentos de Juan II, Murcia-Cádiz, ed. Acad. Alf. $\mathrm{X}$ el Sabio / Univ. de Cádiz / C.S.I.C., 1984, 726 pp.

4091 - ABU MUSTAFA, Kamel: "Los muladies en la Marca Superior y su papel politico durante el emirato omeya", Boletin de la Facultad de Bílucación Alejandria, ed. Univ. de Alejandria, 1988.

4092 - AGUILERA MIRALIES, Rosa; GARCIA EDO, Vicent: "Documents particulars castellonencs del segle XIII escrits en catala", Segon Congres Internacional de"la Llengua Catalana, Valéncia, ed. Institut de Filologia Valenciana, vol. 8, 1989, pp. 227-238. Pleito entre la Orden del Hospital y el señor de la alqueria de Tales sobre el derecho a recibir el impuesto de los mudejares de Tales.

4093 - AINAGA ANDRES, Ma. Isabel: "La repoblación de los antiguos lugares moriscos. Tortoles (Zaragoza). 1610-1770. Consideraciones demograficas", Trriaso, Tarazona, ed. Centro de Est. Turiasoneses, Diput. Provincial no. 8, 1989, pp. 83-105. 
4094 - ALMONACID CLAVERIA, J. A.: "La Kura de Santaveria: estructura politico-administrativa", I Congreso de Historla de Castilla-La Mancha. Musulmanes y Cristianos: La implantación del Feudallsmo, Toledo, ed. Junta de Comunidades de Castilla-La Mancha, vol. V, 1988, pp. 5-20.

4095 - ALVAREZ DELGADO, Yasmina: "Repoblación y frontera en la sierra baja de Cuenca", I Congreso de Historia de Castilla-La Mancha Musulmanes $y$ Cristianos. La implantacion del Feudalismo, Toledo, ed. Junta de Comunidades de Castilla-La Mancha, vol. V. 1988, pp. 145-151.

4096 - AMTGUES, Françols: "La ceramique domestique des ateliers mudéjares de Paterna (Valencia)", Melanges de la Casa de Velazquez, Paris, ed. Casa de Velkzquez, no. 23, 1987, pp. 151-172.

4097 - AMIGUES, Françols: "Premières approches de la céramique commune des ateliers de Paterna (Valencia): L' "Obra Aspra" XIVe.-ZVe. siecles", Malanges de la Casa de Valazquez, Paris, ed. Casa de Veláquez, no. 22, 1986. pp. 27-64.

4098 - ANAWATI, G. C.: "Ia rencontre de deux cultures, en Occident au Moyen Age: dialogue islamo-chrétien et activité misionnaire", Bstudios Lulianos; Palma de Mallorca, ed. Maioricensis Studia Lullistica, n. 81, 1989, pp. 155-178.

4099 - ANDRES SARASA, Jose Luis: Bstructura urbana de Murcia, Murcia, ed. Academia Alfonso X el Sabio, $193 \mathrm{pp}$.

4100 - ANSON CALVO, Ma. Carmen: "Almonacid de la Sierra: un pueblo de moriscos en la encrucijada de la expulsión", Destierros Aragoneses. I. Judios y Moriscos (2a Parte: La expulsión de los Moriscos), Zaragoza, ed. Institución Fernando el Católico, 1988, pp. 303-312.

4101 - ANSON CALVO, Ma. del Carmen: "La expulsión de los moriscos en el Campo de Cariñena", Destlerros Aragoneses. I. Judros y Moriscos (23 Parte: La expulsión de los Moriscos), Zaragoza, ed. Institución Fernando el Católico 1988, pp. 261-272.

4102 - ARAGUAS, Phllippe: "Architecture de brique et architecture mudejar", Mélanges de la Casa de Valazquez, París, ed. Casa de Velazquez, no, 23, 1986, pp. 151-172.

4103 - ARDIT, Manuel: "Los moriscos", Historia del Pueblo Valenciano, Valencia, ed. por el Diario LEVANTE, vol. I, 1988, pp. 433-452.

4104 - ARRIBAS PALAU, Mariano: "El embajador marroqui Ahmad al Gazzal en Cartagena (1766)", Las relaciones internacionales en la España Contemporánea, editado por J. B. Vilar, 1989, 348 pp.

4105 - AVILA, Ma. Luisa (editora): Estudios Onomastico-biograficos de Al-Andalus. II., Granada, ed. C.S.I.C., 1989, 343 pp.

4106 - AYALA MARTINEZ, Carlos de: "Jaime I y la sublevación mudéjar-granadina de 1264", Homenaje al Profesor Juan Torres Fontes, Murcia, Univ. de Murcia, Academia Alfonso X el Sabio, vol. I, 1987, pp. 93-107.

4107 - AZUAR RUIZ, Rafael: Denia islamica. Argueología y poblamiento, Alicante ed. Diputación de Alicante, 1989, 450 pp.+ils.

4108 - AZUAR RUIZ, Rafael: "La conquista de Alicante", En torno al 750 Aniversario. Antecedentes $y$ consecuencias de la conquista de Valencia, Valencia, ed. Consellerfa de Cultura Generalitat Valenciana, vol. II, 1989, pp. 115-140.

4109 - AZUAR RUIZ, Rafael: "El hammam musulmán en Al-Andalus", Los Baños Arabes en el País Valenciano Valencia, ed. Conselleria de Cultura de la Generalitat Valenciana, 1989, pp. 33-43. 
du diwan d'Ibn Al-Arabí", Quaderni di Studi Arabi Venecia, no. 5-6, 1987-1988, pp. 70-72.

4112 - BALAÑa I ABADIA, Pere: "Una metodologia simplificada per a la recerca d'etimologies arabigues: aplicacio al cas de Llorac", Studia in Honorem Profesor M. de Riquer. Quaderns Crema, Barcelona, vol. III, 1988, pp. 11-23.

4113 - BALAÑA I ABADIA, Pere: "Recull bàsic de terminologla juridica catalano-arabiga", Revista de Llengua $i$ Dret, no. 11, 1988, pp. 137-156.

4114 - BALAÑA I ABADIA, Pere: "Reivindicacio del passat islamic de Tortosa (713-1148)", Sharq Al-Andalus. Bstudios Arabes, Alicante, ed. Univ. de Alicante, ne. 6, 1989, pp. 241-246.

4115 - BALAÑA I ABADIA, Pere; GARCIA I FORTUNY, Josep: "El nom de Cabassers. Dades historico-lingüistiques sobre la seva evolucio", Cabaces. Documents $i$ Escrits, Cabacés, 1985, pp. 93-98. Etimologla árabe de esta población del Priorat.

4116 - BALAÑa ABADIA, Pere; GaRCia I FoRTunY, Josep: "Sobre la xufla, un conreu actualment típic del Llevant (antic Sharq Al-Andalus)", Boletin de la Sociedad Castellonense de Cultura. Miscelanea dedicada a la memoria de Angel Sánchez Gozalvo, Castellón de la Plana, ed. Sociedad Castellonense de Cultura, n9. 64, 1988, pp. 293-308.

4117 - BARCELO TORRES, Ma. Carmen: "Una inscripcio arab de Xábia", Xabiga, Xábia, ne. 4, 1988, pp. 55-58.

4118 - BARCELO TORRES, Ma. Carme: "Poblament 1 toponomàstica de la Vall de Gallinera islàmica", Aguaits, Denia, no. 2, tardor-hivern 1988, pp. 5-16.

4119 - BARCELO TORRES, Ma. Garmen: "Poblamiento y toponomastica de la vall de Gallinera islámica", Saitabi, Valencia, ed. Univ. de Valencia, no. 37, 1987, pp. 115-130.

4120 - BARCELO, Carmen: Un tratado catalan medieval de Derecho islamico: El Llibre de la Çuna e Xara Cordoba, 1989, 24+123 pp.

4121 - BARCELO TORRES, Ma. Carmen: "Las yeserias arabes de Onda", Ibn Al-Abbar. Baletín Informativo del Centro de Iniciativas y Turismo de Onda, Onda, n9. 53, 1977, pp. 356-364.

4122 - BARCELO, Carmen; LABARTA, Ana: "Ocho relojes de sol hispanomusulmanes", Al-gantara, Madrid, ed. C.S.I.C., vol. 9/2, 1988, pp. 231-247. El último de los estudiados procede de Sagunto. Esenciales para la regulación del tiempo religioso musulmán.

4123 - BARCELO, Miquel: "E1 rei Akhila i els fills de Witiza: encara un altra recerca", Miscellanea Barcinonensia, Barcelona, ed. Ayuntamiento de Barcelona, any 17, núm. 49, 1978, pp. 59-75.

4124 - BARCELO, Miquel: "VIsperas de feudales. La sociedad del "Sharq Al-Andalus" justo antes de la conquista catalana", España. Al-Andalus. Sefarad: Sintesis y nuevas perspectivas, Salamanca, ed. Univ. de Salaman ca, 1988, pp. 99-112.

4125 - BARCELO, Miquel: "Why and how did Andalusian coins travel to Europa during the Emirate and the Caliphate from 98/716-717 to 403/1012-1013", Revue de l'Occident Musulman et la Mediterranee, Aix-en-Provence, no.' $36,1983 / 2$, pp. 5-18.

4126 - BARCELO, Miquel; CARBONERo, Ma. Antonia; MARTI, R.; ROSSELlo BORDOY, Guillem: "Arqueologlas La "Font Antiga" de Crevillent: Ensayo de descripción arqueologica", Areas. Revista de Cienctas Sociales, Murcia, Editora Regional de Murcia, n9. 9, 1988, pp. 215-231.

4127 - BARCELO, Miquel; KIRCHNER, Helena; LLURO, Josep M.; MARTI, Ramon; TORRES, Jose M.: Arqueología Medieval En las afueras del medievalismon, Barcelona, Ed. Critica, 1988, 285 pp. 
4128 - BASAÑEZ VILLALUENGA, Ma Blanca: La aljama sarracena de Huesca en el siglo XIV, Barcelona, ed. C.S.I.C., 1989, 275 pp.

4129 - BATLLE, Carme: "Uns mercaders de Barcelona al Nord d'Africa a mitjan segle XIII", Acta Historica et Archaeologica Mediaevalia Barcelona, ed. Universitat de Barcelona, no. 10, 1989, pp. 145-157.

4130 - BATLLE, Carmen: "Las relaciones comerciales de Barcelona con la España musulmana a fines del siglo XII e inicio del XIII", Historia Medieval Anales de la Universidad de Alicante, Alicante, ed. Univ, de Alicante, no. 6, 1987, pp. 107-133.

4131 - BAZZANA, André: "Recherches sur la maison morisque", Histoire et Archeologie de I'Habitat Medieval, Iyon, 1986, pp. 127-134.

4132 - BAZZANA, André; CRESSIER, Patrice; GUICHARD, Pierre: Les chateaux ruraux d'Al-Andalus. Histoire et Archeologie dels "husim" du sud-Est de l'Espagne, Madrid, ed. Casa de Velázquez, 1988, $326^{\circ}$ pp.

4133 - BAZZANA, André; GUICHARD, Pierre: "Otra vez, sobre Castellologia", Cuadernos de la Ahambra, Granada, ed. Patronato de la Alhambra, no. 24 1989, pp. 11-14. Polémica con P. López Elum, sobre el castillo de Perputxent.

4134 - BECERRA HORMIGo, Manuel: "La conexión catalana en el derrocamiento de Ismail II", Miscel lania de Textos Medievals. La frontera terrestre $i$ Maritima amb I'IsIam, Barcelona, ed. C.S.I.C., ne. 4, 1988, pp. 301-318. Intromisión de la corona catalano-aragonesa en la politica nazari granadina.

4135 - BECERRA, Manuel: "Las relaciones diplomáticas entre la Corona de Aragón y Granada durante la Guerra de los Dos Pedros. I. Desde 1356 hasta 1359", Acta Historica et Archaeologica Mediaevalia, Barcelona, Univers. de Barcelona, nQ. 9, 1988, pp. 243-260.

4136 - BEJARANo RUBIo, Amparo: "La frontera del Reino de Murcia en la politica castellano-aragonesa del siglo XIII", Alfonso X el Sabio, vida, obra, epoca, Madrid, ed. Sociedad Española de Estudios Medievales, vol. I, 1989, pp. 199-212.

4137 - BELENGUER I CEBRIA, Ernest: "Jaume I", En torno al 750 aniversario. Antecedentes $y$ consecuencias de la conquista de Valencia, Valencia, $e d$. Conselleria de Cultura Generalitat Valenciana, vol. I, 1989, pp. 279-301. CATALUÑA

4138 - BERNABE GUILLAMON, M.; FERNANDEZ, F. V.; MANZANO, J.; POZO, I.; RAMIREZ, E.: "Arquitectura domestica islamica en la ciudad de Murcia", Murcia Musulmana, edición de F. J. FLORES ARROYUELO, Murcia, Ediciones Almudi, 1989, pp. 233-251.

4139 - BERNABE I MAESTRE, Josep: "Obras hidráulicas tradicionales en el regadio de Petrer (Vall del Vinalopo)", Los Paisajes del Agua. Libro Jubilar dedicado al Prof. Antonio Lopez Gomez, Valencia, Universitat de València/ Universitat d'Alacant, 1989, pp. 187-199.

4140 - BERNABE PONS, Luis Fernando; EPALZA, MIkel de: "Els moriscos valencians a l'exili després de l'expulsio del 1609", Afers, Catarroja, ed. Afers, vol. 7, 1988-1989, pp. 207-214.

4141 - BERNABE PONS, Luis Fernando; EPALZA, Mikel de: "Novedades bibliográficas sobre el Corán y Mahoma", Sharq Al-Andalus. Estudios Arabes Alicante, no. 5, 1988, pp. 235-240.

4142 - BERNABEU LOPEZ, Rafael: "Andanzas de los moriscos por tierras requenenses", Crónica del XII Congreso Nacional de Cronistas de España y XVI Asamblea de Cronista Oficiales del Reino de Valencia Valencia, ed. Conseliería de Cultura / Diputación / Ayuntamiento, vol. I, 1988, pp. 71-82. 
4143 - BERNARD, Vincent: "Tres encuentros sobre los moriscos", Areas. Revista de Ciencias Sociales, Murcia, Editora Regional de Murcia, ne. 5, 1985, pp. 74-77.

4144 - BEVIA, Màrius: "Alacant: Banys, aigua i ciutat musulmana", Los Baños Arabes en el Pals Valenciano, Valencia, ed. Consell. de Cultura de la Generalitat Valenciana, 1989, pp. 83-88.

4145 - BEviA, Mârius: "Els banys d'Elx. Primera aportacio", Los Baños Arabes en el Pais Valenciano, Valencia, 1989, pp. 107-111.

4146 - BIENES CALVO, Juan José: "Introducción al estudio de la cerámica musulmana en la ciudad de Tudela", Tvriaso. Monografico: El Islam en Aragón, Tarazona, ed. Centro de Estudios Turisonenses del C.S.I.C., no. 7, 1988, pp. 115-158.

4147 - BLANCO, Ma. Elena et ali: Mudejar en Utebo, Zaragoza, ed. Inst. Fernando el Catolico del C.S.I.C., 1987, 79 pp.

4148 - BLASCO MARTINEZ, Rosa Ma.: "Los moriscos que permanecieron en el Obispado de Orihuela despues de 1609", Sharq Al-Andalus. Bstudios Arabes, Alicante, ed. Univ. de Alicante, no. 6, 1989, pp. 129-147.

4149 - BOIGUES, Carlos: "Los baños árabes en la ciudad de Valencia", Los Baños Arabes en el País Valenciano, Valencia, 1989, pp. 113-131.

4150 - BORRAS, Gonzalo: "Acotaciones a la arquitectura civil mudejar aragonesa", IV Cologio de Arte Aragones, Zaragoza, ed. Diput. General de Aragón, 1986, pp. 11-22.

4151 - BORRAS, Gonzalo: "Arte Mudéjar", Historia del Arte. I. Tomo III de la Enciclopedia Tematica de Aragón, Zaragoza, ed. Moncayo, 1986, pp. 227-296.

4152 - BORRAS, Gonzalo: El arte mudejar de Teruel y su provincia, Teruel, ed. Instit. de Estudios Turolenses, 1987, 84 pp.

4153 - BORRAS, Gonzalo: "La fábrica mudejar de la iglesia conventual: el convento franciscano de San Salvador en Pina de Ebro (Zaragoza)", Artigrama, Zaragoza, no. 3, 1986, pp. 54-58.

4154 - BORRAS, Gonzalo: "El legado del arte mudejar en España", Legados del mundo medieval para la sociedad actual Zaragoza, ed. Inst. Fernando el Católico, 1987, pp. 31-46.

4155 - BORRAS, Gonzalo: "El palacio mudéjar de los arzobispos de Zaragoza", Estudios en Homenaje al Dr. A. Beltrán Martínez, Zaragoza, ed. Univ. de Zaragoza, 1986, pp. 1007-1015.

4156 - BOSCH VILA, Jacinto: El oriente árabe en el desarrollo de la cultura de la Marca Superior, Madrid, ed. Instituto Egipcio de Estudios Islámicos, 1954, 56 pp.

4157 - BRAMON, Dolors: "¿Castores en el Ebro?. A propósito de un texto de Yáqūt sobre los "sammūr" de Zaragoza", Aragón en la Edad Media. VIII. Homenaje al Profesor Emerito Antonio Ubieto Arteta, Zaragoza, ed. Univ. de Zaragoza, no. 8, 1989, pp. 133-137.

4158 - BRAMON, Dolors: "De les rapites catalanes: la institucio islamica del ribat", Antistiana. Butlletr Informatiu, La Ràpita, (Alt Penedés), ed. Grup d'Estứdis Rapitencs, novembre 1989, 5 pp.

4159 - BRAMON, Dolors: "Institucions socials islàmiques i la seua perduració" En torno al 750 aniversario. Antecedentes $y$ consecuencias de la conquista de Valencia, Valencia, ed. Consellería de Cultura Generalitat Valenciana, vol. I, 1989, pp. 107-116. 
4160 - BUNES IBARRA, Miguel Angel de; La imagen de los musulmanes $y$ del Norte de Africa en la España de los siglos XVI y XVII, Madrid, ed. C.S.I.C., 1989.

4161 - BURNETT, Charles: "El Kitāb al-Istāmātis i un manuscrit barceloni d'obres astrologiques 1 astronorniques", Llengua 1 Literaturz Barcelona, ne. 2, 1987, pp. 431-451.

4162 - BURNS, Robert I.: "The Crusade aganist Al-Azraq: a thirteenth-century mudejar revolt in international perspective", The American Historical Review, Philadelphia, vol. 93, no. 1, 1988, pp. 80-106.

4163 - BURNS, Robert I.: Diplomatarium of the Crusader Kingdom of Valencia. The Registered Charters of its Conqueror Jaume I (1257-1256), Princeton, ed. Princeton University Press, 1985, 274 pp.

4164 - BURNS, Robert I.: "La manumisión de un musulmán: un documento doble en Valencia en el 1300", Sharg AI-Andalus. Estudios Arabes, Alicante, ed. Univ. de Alicante, no. 5, 1988, pp. 141-145.

4165 - BURNS, Robert Ignatius: "Regalo para una madre: una muchacha esclava musulmana del nieto de $A b \bar{u}$ Zayd, el señor de Borriol (1301)", Sharq A-Andalus. Estudios Arabes, Alicante, ed. Univ. de Alicante, no. 6, 1989, pp. 115-117.

4166 - BURNS, Robert I.; CHEVEDDEN, Paul E.: "Al-Azraq's Surrender Treaty with Jaume I and Prince Alfonso in 1245: Arabic text and Valencian context", Der Islam. Zeitscrift für Geschichte und Kultur des Islamischen Orients, Berlin, Baud 66, Helft 1, 1989, pp. 1-37.

4167 - BURNS, Robert I.; CHEVEDDEN, Paul E.: "Els mudejars del Regne de Valéncia de la generacio posterior a la croada", Historia del Pals Valencia. De la Conquesta a la Féderacio Hispanica, Barcelona, Edicions 62, 1989, pp. 139-167.

4168 - BUTZER, Karl W.; MATEU, Joan F.; BUTZER, Elisabeth K.: "Origenes de la distribución intercomunitaria del agua en la Sierra de Espadán (País Valenciano)", Los Paisajes del Agua. Libro Jubilar dedicado al Prof. Antonio Lopez Gomez, Valencia, Universitat de Valencia / Univ. d'Alacant 1989, pp. 223-228.

4169 - BUTZER, Karl W.; MATEU, Joan F.; BUTZER, Elisabeth K.; KRAUS, Pavel: "L'origen dels sistemes de regadiu al Pars Valencia: roma o musulma?". Afers, Catarroja, ed. Afers, vol. 7, 1988-1989, pp. 9-68.

C 4170 - CABANES PECOURT, Ma. Desamparados: "Aspectos demograficos de la conquista: Población pre-existente y repoblación en la ciudad de Valencia", Bn torno al 750 aniversario. Antecedentes $y$ consecuencias de la conquista de Valencia, Valencia, ed. Conselleria de Cultura Generalitat Valenciana, vol. I, 1989, pp. 304-318.

$\$ 171$ - CABAÑERO SUBIZA, Bernabé: "La mezquita mudéjar de Santa Margarita de Fraga (Huesca)", Artigrama, Zaragoza, no. 4, 1987, pp. 35-82.

4172 - CAGIGAS, Isidro de las: "Un traité de paix entre le roi Pierre IV d'Aragon et le sultan de Tunis Abu Ishak II (1360)", Hesperis, Rabat, ed. Institut de Hautes Etudes Marocaines, no. 19, 1934, pp. 65-77.

4173 - CALVO GARCIA-TORNEL, Francisco: "Aproximación a la huerta musulmana", Murcia Musulmana, edición de F. J. FLORES ARROYUElo Murcia, Ediciones Almud1, 1989, pp. 385-393. 
4174 - CANTERA MONTENEGRO, Entique: "El Apartamiento de judios y mudéjares en las Diócesis de Osma y Sigüenza a fines del siglo $\mathrm{XV}^{\prime \prime}$, Anuario de Estudios Medievales, Barcelona, ed. C.S.I.C., ne. 17, 1987, pp. 501-510.

4175 - CARMONA GONZALEZ, Alfonso: "LOS ādāb al-qudat, o normas de conducta del fuez islámico", Homenaje al Profesor Juan Torres Fontes, Murcia, 1987, pp. 253-243. SHAA-3219

4176 - CARMONA GONZALEZ, Alfonso: "Ibn Hisám al-Qurtubi y su Mufld li-1hukkām", Quaderni di Studi Arabí Venecia, no. 5-6, 1987-1988, pp. 120-130. Algunos conflictos murcianos entre juristas malikies $y$ autiridades almohades.

4177 - CARMONA GONZALEZ, Alfonso: "Murcia ¿una fundación árabe? (Nuevos datos y conclusiones)", Murcia Musulmana, edición de F. J. FLORES ARROYUELO, Murcia, Ediciones Almudi, 1989, pp. 85-147.

4178 - CARMONA GONZALEZ, Alfonso: "Las vias murcianas de comunicación en época árabe", Caminos de la Región de Murcia, Murcia, 1989, pp. 153-166.

4179 - CARMONA GONZALEZ, Pilar; RIBERA LACOMBA, Albert; LERMA ALEGRIA, Josep V.: "Geoarqueología en la ciudad de Valencia", XVII Congreso Nacional de Arqueología Zaragoza, 1985, pp. 859-873.

4180 - CARO BAROJA, Julio: "Murcia: Divagación sobre un tipo de ciudad mediterránea", Murcia Musulmana, edición de F. J. FLORES ARROYUELO, Murcia, Ediciones Almudr, 1989, pp. 13-37.

4181 - CARRASCO URGOITI, Ma. Soledad: "La cuestión morisca en la narrativa del Síglo de Oro", Destierros Aragoneses. I. Judios y Moriscos (2a Parte, La expulsión de los Moriscos), Zaragoza, ed. Institución Fernando el Católico, 1988, pp. 229-253.

4182 - CARRASCO URGOITI, Ma.' Soledad: "La fiesta de Moros y Cristianos y la cuestión morisca en la España de los Austrias", Actas de las Jornadas sobre teatro popular en España, Madrid, C.S.I.C., 1987, pp. 65-84.

4183 - CARRASCO, Raphäel: "Morisques Anciens et Nouveaus Morisques dans le District Inquisitorial de Cuenca", Mélanges de la Casa de Velázquez, Paris, ed. Casa de Velázquez, no. XXI, 1985, pp. 193-217.

4184 - CARRASCO, Raphäel: "Le prix de la foi: l'Inquisition de Valence et les biens des Morsques (1566-1609)", Actas del III Simposio Internacional de Estudios Moriscos. Las Prácticas Musulmanas de los Moriscos Andaluces (1492-1609), Zaghouan (Túnez), 1989, pp. 43-54.

4185 - CARRERAS Y CANDI, F.: "Relaciones de los vizcondes de Barcelona con los árabes", Homenaje a Don Francisco Codera Madrid, 1904, pp. 207-215.

4186 - CASTELL MAIQUES, Vicent: "Els mossarabs: El cristianisme en Valéncia abans de Jaume I", En torno al 750 aniversario. Antecedentes $y$ consecuencias de la conquista de Valencia, Valencia, ed. Conselleria de Cultura Generalitat Valenciana, vol. I, 1989, pp. 181-198.

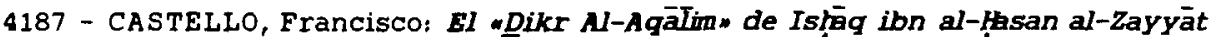
(Tratado de Geografla Universal), Barcelona, ed. Ins. Millás Vallicrosa C.S.I.C. / Univ.Barcelona, 1989, 357 pp.

4188 - CATEURA BENNASAR, P.: "Repoblación, urbanización y comercio: el puerto de la ciudad de Mallorca durante el siglo XIII", Mayurga, Palma de MallorCa, no. 21, 1985-1987, pp. 91-100.

4189-- CERVERA FRAS, Ma. José: "Papel aljamiado de Novallas", Bl Moncayo: Diez años de investigacion arqueologica. Prologo de una labor de futuro, Tarazona, Centro Est.Turiasonenses/Inst. Fdo. el Católico, 1989, pp. 171-172.

4190 - CERVERA FRAS, Ma. José: "Pervivencia de la literatura juridica tradicional entre los moriscos: El "Muhtasar" de al-Tulaytuli", Actas del III Simposio Internacional de Estudios Moriscos. Las Prácticas Musulmanas de los Moriscos Andaluces (1492-1609) Zaghouan (Túnez) 1989 pp. 39-42. 
4191 - CERVERA FRAS, Ma. José La plegaria musulmana en el "Compendio de al-Tulaytulio; transcripción del manuscrito de Sabiñan (Zaragoza), Zaragoza, ed. Inst. Fernando el Católico, 1987, $110 \mathrm{pp}$.

4192 - CERVERA FRAS, Ma. José: "Resistencia cultural de los moriscos a través de sus escritos", Destierros Aragoneses. I. Judios $y$ Moriscos (2s Parte, La expulsión de los Moriscos), Zaragoza, ed. Inst. Fernando el Católico, 1988, pp. $327-330$.

4193 - CERVERA FRAS, Mâ. Jose: "Un tratado juridico musulmán copiado por mudéjares aragoneses. Descripción de los manuscritos del "Muhtasar" de Al-Tulaytuī", Aragón en la Bdad Media. VIII. Homenaje al Profesor Bmerito Antonio Ubieto Arteta, Zaragoza, ed. Univ. de Zaragoza, ne. 8, 1989, pp. 175-183.

4194 - CHALMETA, Pedro: "Estructuras socio-económicas musulmanas", En torno al 750 aniversario. Antecedentes y consecuencias. de la conquista de Valencia, Valencia, ed. Consell. Cultura Generalitat Valenciana, vol. I, 1989, pp. 13-52.

4195 - CODERA Y ZAYDIN, Francisco: "Bibliotecas en España", Revista de Aragón, 1903, Pp. 1-7.

4196 - CODERA Y ZAYDIN, Francisco: "Limites probables de la conquista arabe en la Cordillera Pirenaica", Boletín de la Real Academia de la Historia, Madrid, abril 1906, pp. 3-24.

4197 - COLAS LATORRE, Gregorio: "Los moriscos aragoneses y su expulsion", Destierros Aragoneses. I. Judíos y Moriscos (29 Parte: La expulsión de los Moriscos), Zaragoza, ed. Instit. Fernando el Catolico, 1988, pp. 189-216.

4198 - COLL CONESA, Jaume: "Ceràmica i canvi cultural a la València medieval. L'Impacte de la conquesta", Afers, Catarroja, ed. Afers, vol. 7, 1988-1989, pp. 125-167.

4199 - COLL I ALENTORN, Miquel: Els successors de Vitiza en la zona Nord-Est del domini visigdtic, Barcelona, ed. Reial Acadèmia de Bones Lletres de Barcelona, 1971, 51 pp.

4200 - COLOM, Miquel: "El "Llibre de contemplació" i la llengua arabiga", Studia Lullistica. Miscellanea in Honorem Sebastiani Garctas Palou, Palma de Mallorca, ed. Maioricensis Schola Lullistica, 1989, pp. 15-18.

4201 - COLON, Germán: "El arabismo azarbe/assarp en el Bajo Segura", Miscellanea di Studi Romanzi offerta a Giuliano Gasca Queirazza per il suo 65 compleanno, Torino, Edizioni dell'Orso, 1988, pp. 145-158. Perduración del arabismo "sarb" en el Bajo Segura, con la forma catalana "assarb".

4202 - CORBIN, Henry: Creative imagination in the Sufism if Ibn 'Arabi, Princeton, ed. Princeton University Press, 1969, 406 pp.

4203 - CORRAL LAFUENTE, Jose Luis: "Arquueologla Medieval e Industrial", Bstado Actual de la Arqueología en Aragón, Zaragoza, ed. Institución Fernando el Católico, 1987.

4204 - CORRIENTE, Federico: "Las jarchas valencianas (Algunas "xarajāt" romances en "muwassaht." de poetas andalusies de origen valencianol", Bn torno al 750 aniversario. Antecedentes y consecuencias de la conquista de Valencia, Valencia, ed. Conselleria de Cultura Generalitat Valenciana, vol. I, 1989, pp. 227-236.

4205 - CORRIENTE, Federico: "De nuevo sobre la elegla árabe de Valencia", A-Qantara Madrid, C.S.I.C., ne. 8, 1987, pp. 331-335.

4206 - CORTABARRIA, A.: "La connaissance des textes arabes chez Raymond Martin O. P. et sa position en face de l'Islam", Cahiers de Fanjeux. Islam et Chretiens du Midi (XIIe.-XIVe. 5.), Fanjeaux-Toulousse, no. 18, 1983, pp. 279-300. 
4207 - CORTES, Josepa; FURIO, Antoni; GUICHARD, Pierre; PONS, Vicent: "Les alqueries de la Ribera: assaig d'identificacio i localitzacio", Economia Agraria i Historia Local. I Assemblea d'Historia de la Ribera València ed. Institució Alfons el Magnànim 1981 pp. 209-262

4208 - CRADDOCK, Jerry R.: The Legislative Works of Alfonso $Z$, el Sabio, Research Bibliographies and Checklists, Londres, ed. Grant and Cutler, $1986,248 \mathrm{pp}$.

4209 - CRESSIER, Patrice: "Estructuras hidráulicas antiguas en la provincia de Almerfa: aproximación a una prospección temática global", Homenaje al Padre Tapia. Almeria en la historia, Almeria, ed. Caja de Ahorros, 1988, pp. 207-218.

4210 - CRUSAFONT SABATER, Miquel: "Del morabatín almorávide al florín. Continuidad o ruptura en la Catalunya medieval", I Jarigue de Estudios Numismáticos Hispano-Arabes, Zaragoza, no. 1, 1988, pp. 191-200.

4211 - CRUZ HERNANDEZ, Miguel: "El simbolo del árbol en Ramon liull e Ibn Al-Jǟb", Studia Lullistica. Miscellanea in Honorem Sebastiani Garcias Palou, Palma de Mallorca, ed. Maioricensis Schola Lullistica, 1989, pp. 19-25.

4212 - CUELLA, Ovidio: "Los mudéjares de la comunidad de Calatayud a fines del siglo XIV y comienzos del XV", Papeles Bilbilitanos. Actas del Segundo Encuentro de Estudios Bilbilitanos, Zaragoza, Centro de Est. Bilbilitanos/ Inst. Fernando Católico, vol. II, 1989, pp. 209-225.

$D 4213$ - DELAIGUE, M.-C.: "Possible influence berbère dans la céramique médievale de la région valencienne", Bulletin d'Archeologie Marocaine, Rabat, vol. XV, 1983-1984, pp. 492-522.

4214 - DIAZ BORRAS, Andrés: "Notas sobre los primeros tiempos de la atención valenciana a la redención de cautivos cristianos (1323-1399)", Estudis Castellonencs, Castellón de la Plana, no. 3, 1986, pp. 337-353.

4215 - DIEZ-CORONEL MONTULL, Luis: "La torre de "La Rapita", en Vallfogona de Balaguer", VII Congreso Nacional de Arqueologla. Barcelona, 1960, Zaragoza, 1962, pp. 446-453.

4216 - DIZ ARDID, Emilio; GARCIA MENARQUEZ, Antonio; GEA CALATAYUD, Manuel de: "Norias, cenias, bombillos y otros aparatos elevadores de agua en el Bajo Segura", Ayudas a la Investigacion. 1984-1985, Alicante, ed. Instituto de Estudios "Juan Gil Albert", vol. 2, 1985, pp. 176-189.

4217 - DUBLER, César E.: "Las laderas del Pirineo según Idrisi", Al-Andalus, Madrid-Granada, ed. C.S.I.C., no. 18, 1953, pp. 337-373.

4218 - DURAN GUDIOL, A.: "El eremita San Urbez ¿Mozárabe de Huesca?", Aragon en la Edad Media. VIII. Homenaje al Profesor Emerito Antonio Ubieto Arteta, Zaragoza, ed. Univ. de Zaragoza, no. 8, 1989, pp. 359-362.

4219 - EPALZA, Mikel de: "Al-'arabiyya wa-l-luga al-qataläniyya", [El àrab i la llengua catalana], AI-'ilm ath-thagáfí, suplemento semanal, Rabat, $\mathrm{n}$. 918 , año $20,25-03-1989$, p. 4.

4220 - EPALZA, MIkel de: "El binomi arab-mossarab "Al-Fahs/El Campello", a Lleida", Societat d'onomastica. Butlleti Interior Barcelona, no. 35, maŗ 1989, pág. 32.

4221 - EPALZ̨A, Mikel de: "Caracterización del exilio musulmán: la voz de mudéjares y moriscos", Destierros Aragoneses. I. Judios y Moriscos (2a Parte: La expulsion de los Moriscos), Zaragoza, ed. Instit. Fernando el Catolico, 1988, pp. 217-228.

4222 - EPALZA, Mikel de: "Congresos y publicaciones de historia árabe en época otomana (Túnez)", Awrag, Madrid, ed. I.C.M.A., no. 9, 1988, pp. 217-221.

4223 - EPALZA, MIkel de: "La época árabe-islámica (II)", Historia de las Baleares, Palma de Mallorca, ed. Formentor, Cuad. Biblgr. nq. 19, 1989, pp. 
217-228. Articulo en forma de entrevista en que se desgranan los problemas históricos más importantes de esta época.

4224 - EPALZA, Mikel de: "Estructura, evolució i esplendor de les taifes valencianes", En torno al 750 aniversario. Antecedentes $y$ consecuencias de la conquista de Valencia, Valencia, ed. Consellería de Cultura Generalitat Valenciana, vol. I, 1989, pp. 129-140.

4225 - EPALZA, Mikel de: "Estructura y funciones de los baños islámicos", Los Baños Arabes en el Pals Valenciano, Valencia, ed. Consell. de Cultura Generalitat Valenciana, 1989, pp. 11-24.

4226 - EPALZA, Mikel de: "Etude d'elements urbanistiques d'Al-Andalus", Les Cahiers de Tunisie. Actes du IVe. Congress International d'Histoire et Civilisation du Magrheb, Túnez, tomo 34, no. 137-138, 1986, pp. 136-138.

4227 - EPALZA, Mikel de: "Mobiliario de los baños árabes", Los Baños Arabes en el Pals Valenciano, Valencia, ed. Consellería de C'ultura Generalitat Valenciana, 1989, pp. 79-82.

4228 - EPALZA, MIkel de: "Nota sobre la etimología árabe-islámica de "Riesgo" ", Sharg Al-Andalus. Estudios Arabes, Alicante, ed. Univ, de Alicante, no. 6, 1989 , pp. $185-192$.

4229 - EPALZA, Mikel de: "Note sur l'eau dans les recherches sur l'urbanisme musulman en Espagne", L'eau et la cultura populaice en Méditerranée, Aix-en-Provence, Univ. de Provence, 1989, pp. 23-25.

4230 - EPALZA, Mikel de: "L'ordenacio del territori del Pais Valencia abans de la conguesta, segons Ibn Al-Abbār (segle XIII)", Sharg Al-Andalus. Bstudios Arabes, Alicante, ed. Univ. de Alicante, no. 5, 1988, pp. 41-67.

4231 - EPALZA, Mikel de: "Rites musulmans opposés aux rites chrétiens dans deux textes de morisques tunisiens: Ibrahim Taybili et Anmad Al-Hanafi", Las prácticas musulmanas de los moriscos andaluces (1492-1609), Dirigido por Abdeljelil Temimi, Zaghouan, ed. CEROMDI, 1989, pp. 71-74.

4232 - EPALZA, Míkel de: "Tolerància i intolerància islàmica", Cultura, Barcelona, no. 1, maig 1989, pp. 14-15.

4233 - EPALZA, Mikel de: "La vie intellectuelle en espagnol des Morisques au Maghreb (XVIIe. siècle)", 3e. Syposium International d'Etudes Ottomanes, Zaghouan-Hamamet, 1988, 8 pp.

4234 - EPALZA FERRER, Mikel de; AMENGUAL I BATLE, Josep: "La época árabeislámica (I)", Historia de las Baleares, Palma de Mallorca, ed. Formentor, Cuaderno, no. 18, 1989, pp. 204-216.

4235 - EPALZA, Mikel de: "Sobre el nombre árabe del castillo de la Atalaya de Villena", Revista de Fiestas, Villena, sept. 1989, pag. 110.

4236 - EPALZA, MIkel de; GALDON, Edelmiro et alii: 750 anys. Civilitazio trencada: I'Islam Valencià (Cataleg de I'Exposicio), Valencia, ed. Consell. de Cultura de la General. Valenciana, 1989, $83 \mathrm{pp}$.

4237 - EPALZA, Mikel de; LLOBREGAT, Enrique A. et ali: Baños islamicos en el País Valenciano, Valencia, ed. Consell. de Cultura de la General. Valenciana, 1989, 157 pp.

4238 - ESCO, C.; SENAC, Ph. Un "Hisn" de la Marche Supérieure d'Al-Andalus: Piracés (Huesca)", Melanges de la Casa de Velazguez, Paris, ed. Casa de Velázquez, no. 23, 1987, pp.125-150.

4239 - ESCORIHUELA CASADEMONT, Xavier: "Toponimia de l'Alcora (Pais Valencià), Societat d'onomastica. Butlletr Interior, Barcelona, ed. Societat d'onomàstica, $\mathrm{n} 0.34$, desembre 1988 , pp. 3-12.

4240 - ESTABLES ELDUQUE, José Ma.: "Noticia de una ciudad amurallada y una mezquita en la comarca de Calatayud", Papeles Bilbilitanos. Actas del Segundo Encuentro de Estudios Bilbilitanos, Zaragoza, Centro de Est. Bilbilitanos / Inst. Fernando Católico, vol. I, 1989, pp. 191-198. 
gundo Encuentro de Estudios Bilbilitanos, Zaragoza, Centro de Est. BilbiLitanos / Inst. Fernando Católico, vol. I, 1989, pp. 191-198.

4241 - ESTABLES ELDUQUE, Jose Ma.: "Planimetría del mudejar calatayubi", Papeles Bilbilitanos. Actas del Segundo Encuentro de Estudios Bilbilitanos, Zaragoza, Centro de Est. Bilbilitanos / Inst. Fernando Católico, vol. I, 1989, pp. 199-219.

4242 - ESTAL, Juan Manuel del: "Anexion del Camp d'Alacant al reino de Valencia", Historia Medieval. Anales de la Univ. de Alicante, Alicante, ed. Univ. de Alicante, no. 6, 1987, pp. 229-278.

4243 - ESTAL, Juan Manuel del: Corpus documental del reino de Murcia bajo la soberanfa de Aragón: 1296-1304/5, Alicante, Inst. Estudios "Juan Gil Albert", vol. I, 1985, 471 pp.

4244 - ESTAL, Juan Manuel del: "La incorporación de Alicante al Reino de Valencia", en "El nacimiento del Reino de Valencia", fasciculo de la Historia del Pueblo Valenciano, Valencia, ed. por el Diario LEVANTE, vol. I, 1988, pp. 213-220.

4245 - ESTAL, Juan Manuel del: "Integración de Alicante en el reino de Valencia". En torno al 750 aniversario. Antecedentes $y$ consecuencias de la conquista de Valencia, Valencia, ed. Consellería de Cultura Generalitat Valenciana, vol. II, 1989, pp. 142-162.

4246 - ESTEBAN LATOR, S. I.: "Ibn Sabin de Murcia y su "Budd al-"ärif"", Al-Andalus, Madrid-Granada, ed. C.S.I.C., no. 9, 1944, pp. 371-405.

F 4247 - FAIREN GUILLEN, Victor: "El tribunal de las aguas de Valencia y su proceso: presente $y$ porvenir", En torno al 750 aniversario. Antecedentes $y$ consecuencias de la conquista de Valencia, Valencia, ed. Conselleria de Cultura Generalitat Valenciana, vol. I, 1989, pp. 477-515.

4248 - FEBRER ROMAGUERA, Manuel Vicente: "Los Bellvís: una dinastía mudéjar de alcaides generales de Valencia, Aragón y Principado de Cataluña", Actas del III Simposio Internacional de Mudejarismo (Teruel, 1984). Teruel, Inst. de Estudios Turolenses, 1986, pp. 277-290.

4249 - FERRANDO I FRANCES, Antoni: "Interés historic geografic i toponimic d'un informe militar sobre la Serra d'Espada", Sharg Al-Andalus. Estudios Arabes, Alicante, ed. Univ, de Alicante, no. 5, 1988, pp. 153-162.

4250 - FERRANDO I FRANCES, Antoni: "Ies interrelacions lingüistiques en la València doscentista. Comentaris a les aportacions de Robert I. Burns", Afers, Catarroja, ed. Afers, vol. 7, 1988-1989, pp. 215-229.

4251 - FERqER CLARI, Agustín; PELUFO PEREZ, Ma. Angeles: "Estudio de las cerámicas esgrafiadas de Al-Gezira Sugar", Al-Gezira, Alcira, no. 4-5, octubre 1988, pp. 47-73.

4252 - FERRER I MALLOL, Ma. Teresa: Organitzacio $i$ defensa d'un territori fronterer. La Governació d'Oriola en el segle IIV, Barcelona, ed. C.S.I.C., 1989.

4253 - FERRER I MALLOL, Ma. Teresa: "Toponimia medieval d'oriola", Miscel-lania d'Homenatge a En ric Moreu-Rey, Montserrat, Publicacions de l'Abadia de Montserrat, vol. II, 1988, pp. 195-211.

4254 - FERRER NAVARRo, Ramón: "Aspectes demografics de la conquista. Pobla ció preexistent i repoblacio en el regne de València", En torno al 750 Aniversario. Antecedentes y consecuencias de la conquista de Valencia, Valencia, ed. Consellería de Cultura Generalitat Valenciana, vol. I, 1989, pp. 319-333.

4255 - FERRER, Agustín; MARTINEZ, Francisco; RIVAS, Luis: Informe Preliminar sobre las excavaciones arqueologicas del «Mercat Vell,, Alzira, Valencia Alzira ed. Ajuntament d'Alzira, 1988, $16 \mathrm{pp}$. 
4256 - FERRER, Ramón; GUINOT, Enric: "La repoblación valenciana medieval", Historia del Pueblo Valenciano, Valencia, ed. por el Diario LEVANTE, vol. I 1988, pp. 241-260.

4257 - FLORES ARROYUELO, Francisco J.: Los Ultimos Moriscos (Valle de Ricote, 1614), Murcia, ed. Public. de la Comunidad Autónoma de Mucia, 1989, 202 pp.

4258 - FLORES ARROYUELO, Francisco J.: "Urbanismo y colonizacion: Mursiyya, ciudad nueva de la Küra de Tudmir (Etnografía histórica)", Murcia Musulmana, edición de F. J. FLORES ARROYUELO, Murcia, Ediciones Almudi, 1989, pp. 39-54.

4259 - FONT RIUS, Josep Ma.: "La conquesta: un procés historic", En torno al 750 aniversario. Antecedentes $y$ consecuencias de la conguista de Valencia Valencia, ed. Consell. de Cultura Generalitat Valenciana, vol. I 1989, pp. 237-278.

4260 - FONTENLA BALLESTA, Salvador: "Los hallazgos numismáticos de los Baños árabes de Santa Eulalia (Murcia)", Boletín de la Asociación Española de Orientalistas, Madrid, vol. 24, 1988, pp. 455-458.

4261 - FONTENLA BALLESTA, Salvador: "Las monedas hispano-musulmanas del Museo de Murcia", Boletín de la Asociación Bspañola de Orientalistas, Madrid, ed. Asociación Española de Orientalistas, no. 23, 1987, pp. 387-392. En base a las monedas nazaries del Tesorillo de Cuevas de Almanzora y otras de procedencia desconocida.

4262 - FOREY, A. J.: "Notes on irrigation in north-easter Spain during the XII and XIII century", Anuario de Bstudios Medievales, Barcelona, ed. C.S.I.C., no. 17, 1987, pp. 119-132.

4263 - FRANCO SANCHEZ, Francisco: "Identificación de la tumba de los sid Bono en Benifato (Alicante)", Sharg M-Andalus. Bstudios Arabes, Alicante, ed. Univ. de Alicante, no. 5, 1988, pp. 181-186.

4264 - FRANCO SANCHEZ, Francisco: "Noticias de epoca islamica sobre inundaciones fluviales en el Baix Vinalopo y en la Vega Baja del Segura", Avenidas fluviales e inundaciones en la cuenca del Mediterraneo, ed. A. GIL OLCINA Y A. MORALES GIL, Alicąnte, ed. Univ. de Alicante / C.A.M. 1989, pp. 375-394.

4265 - FRANCO SANCHEZ, Francisco: "En torno de la ubicación de la fortaleza islámica de Qalaşt: La importancia economica y estratégica del rio Júcar", Espacio. Tiempo y Forma. Serie III. Historla Medieval. Homenaje al Prot.Eloy Benito Ruano, Madrid, ed. U.N.E.D., Serie III, vol. 1, 1989, pp. 193-203.

4266 - FRANCO SANCHEZ, Francisco: "L'urbanisme musulmà d'ontinyent", Ontinyent. Bstudis $i$ Documents, Ontinyent, ed. Ajuntament d'ontinyent, ne. 5 , 1989, pp. 23-27.

4267 - FRANCO SANCHEZ, Francisco; EPALZA, Míkel de: "Bibliografía sobre temas árabes del Sharq Al-Andalus. Apéndice V", Sharg Al-Andalus. Estudios Arabes, Alicante, no. 5, 1988, pp. 259-287.

4268 - FUENTE COBOS, Concepción de la: "La morería de Terrer hasta comienzos del siglo XV", Papeles Bilbilitanos. Actas del Segundo Encuentro de Estudios Bilbilitanos, Zaragoza, ed. Centro de Est. Bilbilitanos / Inst. Fernando Católico, vol. II, 1989, pp. 251-257.

4269 - FURIo, Antoni; GARCIA OLIVER, Ferran: "La sociedad rural en le Baja Edad Media", Historia del Pueblo Valenciano, Valencia, ed. por el Diario LEVANTE, vol. I, 1988, pp. 321-340.

4270 - FURIO, Antoni; GARCIA, Ferran: "Dificultats agraries en la formacio i consolidacio del feudalisme al Pais Valencia", Bstudi General La Formació i Expansio del Feudalisme Catala, Girona, ed. Col legi Universitari de Girona, ne. 5-6, 1985-86, pp. 291-310. 
4271 - FUSTER RUIZ, F.: "Uno de los primeros textos bibliográficos sobre la arqueologla de Albacete", Homenaje a samuel de los Santos, Albacete, ed. Inst. de Estudios Albacetenes, 1989, pp. 53-58.

4272 - GAFSI, Abdel Hakim: "Crues, inondations et controle de l'eau dans quelques villages moriscos andalous de Tunisie", Averidas fluviales e inundaciones en la cuenca del Mediterraneo, ed. A. GIL OLCINA y A. MORALES GIL, Alicante, ed. Univ. de Alicante / C.A.M., 1989, pp. 403-414.

4273 - GARCIA ANTON, José, "Castillos musulmanes que dominaban la via Cartagena-Murcia", Historia de Cartagena Tomo V: Alta Bdad Medta (aiglos vin al XIII), Murcia, ed. Mediterráneo, Tomo V, 1986.

4274 - GARCIA ANTON, José: "Cautiverio, canjes y rescates en la frontera entre Lorca y Vera en los últimos tiempos nazaries", Homenaje al Prof. Juan Torres Fontes, Murcia, ed. Univ. de Murcia / Acad. Alfonso X el Sabio, vol. I, 1987, pp. 547-559.

4275 - GARCIA ANTON, José "La circulación monetaria en Cartagena. Siglos XI-XII", Historia de Cartagena, Tomo V: Alta Edad Media (siglos VIII al XIII), Murcla, ed. Mediterráneo, 1986.

4276 - GARCIA ANTON, José Fortificaciones en la costa de Aguilas (Siglo IVI al XIX). La Torre y Castillo de San Juan y la Torre de Cope, Murcia, ed. CajaMurcia, 1988, 101 pp. Origen como defensas costeras frente a los corsarios norteafricanos.

4277 - GARCIA ANTON, José: "Las murallas islamicas de Murcia", Murcia Musulmana, edición de F. J. FLORES ARROYUELO, Murcia, Ediciones Almudr, 1989, pp. 199-214.

4278 - GARCIA ANTON, José: "Relaciones fronterizas entre los reinos de Murcia y Granada en los finales del siglo XV. Aspectos militares", Andalucia entre Oriente y Occid. (1236-1492). Actas del V Col. Historia Medieval de Andalucia, Córdoba, ed. Excma. Diputación de Córdoba, 1988, pp. 377-383.

4279 - GARCIA ANTON, Jose: "Las rutas de Todmir", Caminos de la Regín de Murcia, Murcia, 1989, pp. 139-149.

4280 - GARCIA ANTON, José: "Là tolerancia religiosa en la frontera de Murcia y Granada en los últimos tiempos del reino nazarI", Mvrgetana Murcia, ed. Academia Alfonso X el Sabio, n9. 77, 1980, pp. 133-143.

4281 - GARCIA ARENAL, Mercedes (ed.): Relaciones de la Peninsula Iberica con el Mágreb (Siglos XIII-XVT). Actas del Cologuto (Madrid, 17-18 diciembre, 1987), Madrid, ed. C.S.I.C. / I.H.A.C., 1988, 678 pp.

4282 - GARCIA BALLESTER, Luis: "La ciencia en Valencia despues de la conquista". Bn torno al 750 aniversario. Antecedentes y consecuencias de la conquista de Valencia Valencia, ed. Consell. de Cultura Generalitat Valenciana, vol. II, 1989, pp. 239-254.

4283 - GARCIA DE LA TORRE, J.: "Repercusiones en el Reino de Mallorca de la expulsión de los moriscos, Mayurga, Palma de Mallorca, ne. 21, 1985-87, pp. 191-195

4284 - GARCIA EDO, Vicente: Onda en el aiglo XII (Notas para su estudio), Onda, ed. Ayuntamiento de onda, $1988,156 \mathrm{pp}$.

4285 - GARCIA EDO, Vicente: "Un plet per les aigües del riu de Sonella entre la vila d'Onda i l'aljama mora de Tales (1310-1322)", Mralcamp. Butllet d'Estudis Onders, onda, no. 3, 1987, pp. 75-110.

4286 - GARCIA EDO, Vicente: Segorbe en el siglo XIII: notas para su estudio, Segorbe, ed. Ayuntamiento de Segorbe, 1987, 140 pp.

4287 - GARCKA EDO, Vicente (prólogo): Las yeserias árabes de Onda, Onda, ed. Diputacion Provincial de Castellón, 1989, 5 pp.+fotos. 
4289 - GARCIA GARIJO, Eneida: "La influencia de la música árabe en la española desde mediados del s. XIX hasta los años 30", Sharg M-Andalus. Estudios Arabes, Alicante, ed. Univ. de Alicante, no. 5, 1988, pp. 69-88.

4290 - GARCIA GOMEZ, Emilio: "El gran zejjel marroqui del ciego de Zarhūn. Versión personal", Boletín de la Real Academia de la Historia, Madrid, no. 186, enero-abril 1989, pp. 1-45. En este poema del siglo XIV son mencionados Girona, Murcia, "Liqant" o Alicante, ya cristianos.

4291 - GARCIA GUATAS, Manuel; ESTEBAN L., Juan F.: "Noticia sobre el hallazgo de un tejido musulmán", Artigrama, Zaragoza, no. 3, 1986, pp. 29-34. Tiraz con "basmala" hallado en la iglesia de Calls, en Huesca.

4292 - GARCIA I MAS, Alfred; MARTINEZ I CORBI, Carolina: "El Port de Cap de l'Alfub al segle XVI: primer intent de construccio d'un moll", La Rella, Elx, no. 7, maig 1989, pp. 23-30. Santa Pola, embarque de Moriscos, ataques magrebles $y$ captura de presos.

4293 - GARCIA MENARGUEZ, Antonio: "Sobre la localización del topónimo Almodovar en la desembocadura del Segura", Sharg Al-Andalus. Estudios Arabes, Alicante, ed. Univ. de Alicante, no. 6, 1989, pp. 159-167.

4294 - GARCIA SANZ, Arcadi: "La carta puebla de Onda de 1248. Marco histórico y juridico del documento", Miralcamp. Butlletr d'Bstudis Onders, Onda, no. 1, 1989, pp. 7-27. Conquista catalano-aragonesa de Onda.

4295 - GARULO, Teresa: "Una epistola de Ibn Sahl de Sevilla (s. XIII)", Quaderni di Studi Arabi, Venecia, no. 5-6, 1987-1988, pp. 292-302. Relaciones con poetas y politicos de Murcia y Cartagena.

4296 - GIL FARRES, Octavio: "La circulación monetaria en la Peninsula hispánica entre 711 y 1100 de J.C.", Quaderni Tucinesi de Numismatica e Antichita Classiche, Lugano, ne. 10, 1981, pp. 375-397.

4297 - GIL GARCIA, Ma. Pilar: "Conflictos sociales y oposición étnica: la comunidad mudejar de Crevillente, 1420", Actas del III Simposio Internacional de Mudejarismo (Teruel, 1984), Teruel, ed. Instituto de Estudios Turolenses, 1986, pp. 305-312.

4298 - GIL SAURA, E.: "La expulsión de los moriscos: analisis de las cuentas de la bailía de Alzira. Administración y adjudicación de bienes", Hispania, Madrid, no. 46, 1986, pp. 99-114.

4299 - GLICK, Thomas F: " Las técnicas hidrálicas antes y después de la conquista", En torno al 750 aniversario. Antecedentes y consecuencias de la conquista de Valencia, Valencia, ed. Consell. de Cultura Generalitat Valenciana, vol. I, 1989, pp. 53-71.

4300 - GLOTON, Maurice: Muh-1-Dín Ibn 'Arabi Traite de l'amour, Paris, ed. A. Michel, 1986, 314 pp.

4301 - GOMEZ VALENZUELA, Manuel: "La Aljama de Letux y el Concejo de Pertusa: los vasallos musulmanes $y$ cristianos de don Pedro de Bardaxi en 1453", Destierros Aragoneses. I. Judios y Moriscos (2a Parte: La expulsión de los Moriscos), Zaragoza, ed. Inst. Fernando el Católico, 1988, pp. 273-290.

4302 - GONZALEZ BALDOVI, Maria: "Els banys arabs de Xativa i els seus ravals", Los Buños Arabes en el Pafs Valenciano, Valencia, 1989, pp. 133-156.

4303 - GONZALEZ BLANCO, Antonio: "El nombre de Murcia: Nuevas perspectivas para su estudio", Murcia Musulmana edición de F. J. FLORES ARROYUELO, Murcia, Ediciones Almudi, 1989, pp. 75-84.

4304 - GONZALEZ BLANCO, A.: "La toponimia del municipio de Fortuna la Cueva Negra de Fortuna (Murcia)", Antigüedad $y$ Cristianismo. IV, Murcia, ed. Univ. de Murcia, vol. IV, 1987, pp. 63-83.

4305 - GONZALEZ BLANCO, A.; LILLO, P.; SELVA, A.; JIMENES, J.; CARMONA, A.; PASCUAL, L.: "La Cueva de "la Camareta", refugio ibérico, eremitorio 
4305 - GONZALEZ BLANCO, A.; LILLO, P.; SELVA, A.; JIMENES, J.; CARMONA, A.; PASCUAL, L.: "La Cueva de "la Camareta", refugio iberico, eremitorio cristiano y rincón misterioso para árabes y foráneos hasta el dia de hoy. Sus graffitti", IVI Congreso Nacional de Argueologla (Murcia-Cartagena, 1981), Zaragoza, 1983, pp. 1023 y ss.

4306 - GONZALEZ, Ana: "Inquisición en las fronteras del Mediterráneo. Historia de los renegados (1540-1694)", Areas. Revista de Ciencias Sociales, Murcia, Editora Regional de Murcia, n2. 9, 1988, pp. 51-74.

4307 - GRAU MONTSERRAT, Manuel: "Arabismes en la Tinença de Benifassà (Ports de Morella)", Boletín de Amigos de Morella y su Comarca Morella, vol. VII, 1985, PP. 29-32.

4308 - GRUP D'ESTUDIS RAPITENCS: "Petita historia d'un poble", Antistiana. Butlletr Informatiu, La Ràpita (Alt Penedés), ed. Grup d'Estudis Rapitencs novembre 1989,6 pp.

4309 - GUICHARD, Pierre: "A propos de "Rahals" de l'Espagne Orientale", Miscelánea Medieval Murciana, Murcia, ed. Univ. de Murcia, no. 15, 1989, pp. 9-24.

4310 - GUICHARD, Pierre: "Els "Berbers de València" i la delimitacio del País Valencia a l'alta edat mitjana", Afers, Catarroja, ed. Afers, vol. 7, 1988-1989, pp. 69-85.

4311 - GUICHARD, Pierre: "Otra vez sobre un viejo problema: orientalismo y occidentalismo en la civilización de la España musulmana", En torno al 750 aniversario. Antecedentes y consecuencias de la conquista de Valencia, Valencia, ed. Cons. de Cultura Generalitat Valenciana, vol. I, 1989, pp. 73-96.

4312 - GUICHARD, Pierre: "Le problème des structures agraires en Al-Andalus avant la conquête chrétienne", Andalucia entre Oriente $y$ Occidente (1236-1492). Actas del V Cololquio de Historia Medieval de Andalucla, Córdoba, Excma. Diputación de Cordoba, 1988, pp. 161-170.

4313 - GUICHARD, Pierre: "Le Sarq Al-Andalus, l'orient et le Maghreb aux XII et XIII siecles: réflexions sur l'évolution politique de l'Espagne musulmane", Relaciones de la Península Iberica con el Mágreb (Siglos XIII-XVI). Actas del Coloquio, Madrid, ed. C.S.I.C. / I.H.A.C., 1988, pp. 1-20.

4314 - GUICHARD, Pierre: "El siglo XIII valenciano: Del sistema socio-político "tributario-mercantil" musulmán al regimen señorial y feudal cristiano", Areas. Revista de Ciencias Sociales, Murcia, Editora Regional de Murcia, no. Extra 1986, pp. 53-58.

4315 - GUINOT RODRIGUEZ, EnTiC: Feudalismo en expansion en el norte valenciano. Antecedentes y desarrollo del señorio de la Orden de Montesa. Siglos XIII y XIV, Castellón de la Plana, ed. Diputación, 1986, 446 pp.

4316 - GUIRALT BALAGUERO, Josep: "I'arqueologia andalusina a les nostres terres", Recerques Terres de Ponent, Solsona, no. 9, 1988, p. 125.

4317 - GUIRALT BALAGUERO, Josep; BENSENY I GEA, J.: "Castell d'en Txelis, primeres dades arqueoldgiques", La Noguera Estudis, Balaguer, no. 2, 1987 , p. 193.

4318 - GUIRAL, Jacqueline: "Les relacions comercials del Regne de València amb Berberia al segle XV", Valencia, un mercat medieval, editat per Antoni FURIo, València, ed. Diputacio Provincial de Valéncia, 1985, pp. 277-313.

4319 - GUITART APARICIO, Cristóbal: "El conjunto fortificado de Calatayud", Papeles Bilbilitanos, Calatayud, 1981, pp. 57-75.

4320 - GUTIERREZ DE VELASCO, Anotonio: "Pedro IV y los musulmanes. Maniobras diplomáticas del "Ceremonioson (Años 1357-1358)", Revista de Historia Jerónimo Zurita, Zaragoza, ed. Inst. Fernando el Católico, no. 53-54, 1986, pp. 37-42. Durante la Guerra de los Dos Pedros, el "Ceremonios" 
intenta provocar una revuelta mudejar en andalusi, y se alfa con el rey de Fez.

4321 - GUTIERREZ LLORET, SOnia: Cerámica común paleoandalust del sur de Alicante (Siglos VII-X), Alicante, ed. Caja de Ahorros Provincial de Alicante, $1988,290 \mathrm{pp}$.

4322 - HARRAS, 'Abd Al-Salām; 'ARĀB, Sa'id Almad: Ibn Al-Abbār. Durar al-simt $\bar{A} i$ jabar al-sibt Tetuán, ed. Karimádis, $1972,26+90$, pp.

4323 - HARVEY, L. P.: "LOS moriscos y los cinco pilares del Islam", Actas del II Simposio Internacional de Estudios Moriscos. Las Prácticas Musulmanas de los Moriscos Andaluces (1492-1609), Zaghouan (Túnez), 1989, pp. 93-97.

4324 - HATAMLA, A.: "Rebelión de Mujahid Salim Almanzor en la Sierra de Espadán (Valencia) en tiempos de Carlos V", Actas del IrI Simposio Internacional de Estudios Moriscos. Las Prácticas Musulmanas de los Moriscos Andaluces (1492-1609, Zaghouan (Túnez), ed. CEROMDI, 1989.

4325 - HERNANDEZ JIMENEZ, Félix: "Šumit = Granja de Somed. El sumīt de Yāqūt corrige un texto del Moro Rasis", Al-Andalus, Madrid-Granada, ed. C.S.I.C., no. 7, 1942, pp. 339-345.

4326 - HINOJOSA MONTALVO, José: "Armamento de naves y comercio con el Reino de Granada a principios del siglo XV", Andalucia entre Oriente $y$ occidente (1236-1492). Actas del V Col. Historia Medieval de Andalucia, Cordoba, ed. Diputación de Córdoba, 1988, pp. 643-657. Comercio de los reinos de Valencia y Granada.

4327 - hINOJOSA MONTALVO, José: "Cristianos, mudéjares y granadinos en la Gobernación de Orihuela", Cologuio de Historia Medieval andaluza. Relaciones exteriores del Reino de Granada, Almeria, ed Inst. de Estudios Almerienses, 1988, pp. 323-342.

4328 - HINOJOSA MONTALVO, José: "La economía agropecuaria alicantina en tiempos de Alfonso X: Aproximación a su estudio", Historia Medieval. Anales de la Universidad de Alicante, Alicante, ed. Univ. de Alicante, no. 6, 1987, pp. $159-173$.

4329 - HINOJOSA MONTALVO, José: "Las relaciones entre Valencia y Granada durante el siglo XV: balance de una investigación", Estudios sobre Málaga $y$ el Reino de Granada en el V Centenario de la conquista, Málaga, ed. Diputación Provincial de Máaga, 1987, pp. 83-111.

4330 - HOENERBACH, Wilheim: "Cuatro documentos mudejares originarios de Cataluna y de Levante", Homenaje al P. Dario Cabanelas Rodriguez, O.F.M., con motivo de su LXX Aniversario, Granada, ed. Univ. de Granada, 1987, pp. $369-379$.

4331 - FATÃMLE, Muhammad: "Muriskîyū valensiya tahta watá al-sulta al-dinìya wa-1-siyäsiya fí 'and al-malik Felipe al-talit 1598-1621", Diräsä́, Amán, no. 10, vol. XIV, 1987, pp. 95-124.

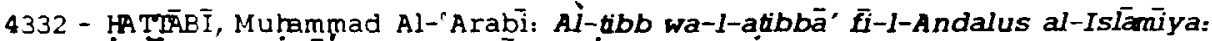
dirăsa wa-tarăgim wa-nușụs Beirut, ed. Dâr al-Garb al-Islâmí, 1988, 2 vols.

I 4333 - IDANEZ SANCHEZ, José F.; RAMIREZ SEGURA, Esperanza: "Cerámica hispano-musulmana procedente del casco urbano de Albacete", I Congreso de Mistoria de Castilla-La Mancha. Musulmanes y Cristianos. La implantacion del Feudalismo, Toledo, ed. Junta de Comunidades de Castilla-La Mancha, vol. V, 1988, pp. 85-94.

4334 - ISIEGAS MUNOZ, Valentín; SANCHO NAVARRO, Lucla: "Estructura mudejar de la iglesia de San Juan Bautista, en Illueca", Papeles Bilbilitanos. Actas del Segundo Encuentro de Estudios Bilbilitanos, Zaragoza, Centro de Est. Bilbilitanos / Inst. Fernando Católico, vol. I, 1989, pp. 317-321. 
4336 - IVARS PEREZ, Josep: "Els banys arabs d'Alzira", Los Baños Arabes en el País Valenciano, Valencia, ed. Consellería de Cultura de la Generalitat, 1989, Pp. 89-94.

4337 - IVARS EEREZ, Josep; GISBERT SANTONJA, Josep A.: "Els banys àrabs a la ciutat de Dènia", Los Baños Arabes en el País Valenciano, Valencia, 1989, pp. $97-105$.

I 4338 - LABARTA, Ana: "El adjetivo "Zaragocf" en castellano", Aragón en la Edad Media. VIII. Homenaje al Profesor Emérito Antonio Ubieto Arteta, Zaragoza, ed. Univ. de Zaragoza, no. 8. 1989, pp. 359-362.

4339 - LABARTA, Ana: "La aljama de musulmanes de Calatorao nombra procurador (documento árabe de 1451)", Al-Qantara, Madrid, C.S.I.C., vol. 9/2, 1988, pp. 511-518.

4340 - LABARTA, Ana; BARCELo, Carmen: "Los documentos árabes del Archivo lunicipal de Novelda (Alicante)", Saitabi, Valencia, ed. Univ. de Valencia, no. 38, 1988, pp. 119-139.

4341 - LACARRA, José María: La reconguista española y la repoblación del país, Zaragoza, ed. Instituto de Estudios Pirenaicos, 1951.

4342 - IAGARDERE, V.: "L'unificateur du malikisme oriental et occidental a Alexandrie: Abü Bakr At-Turtüs'", Revue de l'occident Musulman et la Mediterrané, Aix-en-Proverice; no. 31/1, 1981, pp. 47-61.

4343 - LARQUIE, Claude: " L'eglise et le commerce des hommes en Méditerranée: l'exemple des rachats de chrétiens au XVIIe. siècle", Melanges de la Casa de Velázquez, Parls, ed. Casa de Velázquez, no. 22, 1986, pp. 305-324.

4344 - LAVADO PARADINAS, Pedro J.: "Los baños árabes y judíos en la España medieval", Los Baños Arabes en el País Valenciano, valencia, ed. Consell. de Cultura General. Valenciana, 1989, pp. 45-78,

4345 - LAVADO PARADINAS, Pedro J.: "De Re islamica en Aragón: exposiciones e investigaciones sobre la cultura islamica aragonesa", Artigrama, Zaragoza, no. 4 1987, pp. 364-374.

4346 - LEDESMA RUBIO, Ma. Luisa: "Los mudéjares aragoneses: de la convivencia a la ruptura", Destierros Aragoneses. I. Judfos y Moriscos (2a Parte: La expulsion de los Moriscos), Zaragoza, ed. Instit. Fernando el Católico 1988, pp. 171-188.

4347 - LLOBREGAT, Enrique A.: "L'Islam a les terres valencianes: ¿Pont o frontera?", En torno al 750 aniversario. Antecedentes $y$ consecuencias de la conquista de Valencia, Valencia, ed. Consell. de Cultura General. Valenciana, vol. I, 1989, pp. 141-158.

4348 - LLOBREGAT, Enrique A.: "Las termas romanas como precedente del "hammam" islámico", Los Baños Arabes en el Pals Valenciano, Valencia, ed. Consell. de Cultura de la General. Valenciana, 1989, pp. 25-31.

4349 - LLOPART, Judit; MARUGAN, Carme Ma.; SANCHO, Marta: "El Qānat de la Sinia, a Olesa de Bonesvalls. Un sistema de captació d'aigues", Acta Historica et Archaeologica Mediaevalia, Barcelona, ed. Universitat de Barcelona, no. 9, 1988, pp. 443-455.

4350 - LOMAX, Derek W.: "Apostillas a la repoblación de Alcaraz", Congreso de Historia de Albacete. 8-11 de diciembre de 1983. II. Edad Media, Albacete, ed. Inst. Estudios Albacetenses/C.S.I.C., vol. II, 1984, pp. 19-30.

4351 - LOMBA FUENTES, Joaquin: "Apuntes sobre la significación de Ibn "Arabi", Homenaje al Profesor Juan Torres Fontes, Murcia, 1987, pp. 901-911.

4352 - LOMBA FUENTES, Joaquin: "Avempace y Ben Paqūia", Aragón en el mundo, Zaragoza, ed. Caja de Ahorros, 1988, pp. 64-73.

4353 - LOMBA FUENTES, Joaquín: "El filosofo Ibn Al-Sīd y su paso por Albarracin y Zaragoza", Studium, Teruel, 1987, pp. 73-85. 
4353 - LOMBA FUENTES, Joaquin: "El filosofo Ibn Al-sīd y su paso por Albarracin y Zaragoza", studium Teruel, 1987, pp. 73-85.

4354 - LOMBA FUENTES, Joaquín: "Ibn Pagūda y la ciencia del corazón", Homenaje a Alfonso Candau, Valladolid, 1988, pp. 183-207.

4355 - LOMBA FUENTES, Joaquín: "La relación del hombre con la naturaleza en el Islam", Ecología y Culturas, Madrid, ed. Unviersidad de Comillas, 1988, pp. 157-171.

4356 - LOMBA FUENTES, Joaquin: "Significación de la filosofia islámica en Zaragoza", Aragón en la Edad Media. VIII. Homenaje al Profesor Emerito Antonio Ubieto Arteta, Zaragoza, ed. Univ. de Zaragoza, no. 8, 1989, pp. 441-448.

4357 - LOPEZ ASENSIO, Alvaro: "Caracteres de construcción en las fortalezas musulmanas de la zona de Calatayud", Papeles Bilbilitanos. Actas del Segundo Encuentro de Estudios Bilbilitanos, Zaragoza, ed. Centro de Est. Bilbilitanos / Inst. Fernando Católico, vol. I, 1989, pp. 181-190.

4358 - LOPEZ ASENSIO, Alvaro: "Sistema táctico-defensivo musulmán en la ribera del Jiloca", Papeles Bilbilitanos. Actas del Segundo Encuentro de Estudios Bilbilitanos, Zaragoza, ed. Centro de Est. Bilbilitanos / Inst. Fernando Católico, vol. I, 1989, pp. 171-179.

4359 - LOPEZ DE COCA CASTAÑER, JOSÉ Enrique: "LOS mudejares valencianos y el reino nazari de Granada. Propuestas para una investigación", En la España Medieval. II. Estudios en mernoria del Prof. D. Salvador de Moxó, Madrid, ed. Univ. Complutense, vol. I, 1982, pp. 643-666.

4360 - LOPEZ ELUM, Pedro: "La conquista", en "El nacimiento del Reino de Valencia", fasciculo de la Historia del Pueblo Valenciano Valencia ed. por el Diario LEVANTE, vol. I 1988, pp. 201-212.

4361 - LOPEZ ESTRADA, Francisco: "Notas al manuscrito aragonés de la "Embajada a Tamorlán", Anuario de Estudios Medievales, Barcelona, ed. C.S.I.C., no. 17, 1987, pp. 371-378.

4362 - LOPEZ SAMPEDRO, Germán: "La avanzada del Masilon", Papeles Bilbilitanos. Actas del Segundo Encuentro de Estudios Bilbilitanos Zaragoza, Centro de Est. Bilbilitanos / Inst. Fernando Catolico, vol. I, 1989, pp. 163-169. Sistema defensivo de Calatayud.

4363 - LOPEZ SAMPEDRO, Germán: "Dos ventanas destruidas en el castillo de Ayub", Papeles Bilbilitanos. Actas del Segundo Encuentro de Estudios Bilbilitanos, Zaragoza, Centro de Est. Bilbilitanos / Inst. Fernando Católico, vol. I, 1989, pp. 221-224.

$\$ 364$ - LOPEZ SAMPEDRO, Germán: "Medallones mudéjares desconocidos en Calatayud", Papeles Bilbilitanos. Actas del Segundo Encuentro de Estudios Bilbilitanos, Zaragoza, ed. Centro de Est. Bilbilitanos / Inst. Fernando Catolíco, vol. I, 1989, pp. 257-269.

4365 - LOSADA CAMPO, Teresa: "La inmigración árabo-musulmana en Cataluña en los últimos 20 años", Boletín Informativo. Secretariado de la C. E. de Relaciones Interconfesionales, Madrid, no. 27, octubre-diciembre 1988, pp. 18-23.

4366 - LOURIE, Elena: "La colonización cristiana de Menorca durante el reinado de Alfonso II "el Liberal" rey de Aragón", Analecta Sacra Tarraconensia, Barcelona, ne. III-IV, 1980-1981, pp. 135-136.

M 4367 - MACAIRE, Pierre: "Mallorca y el comercio con el Mediterráneo oriental", Estudis Balearics, Palma de Mallorca, no. 15, 1984, pp. 43-67.

4368 - MAILlO SALGADO, Felipe: IBN PUBAYR, Muṭmmad b. Ahmad: A través del Oriente (EI siglo XII ante los ojos), Barcelona, ed. Serval, 1988, 429 pp.

4369 - MAKDISI, George: "The madrasa in Spain: Some remarks", Revue de l'Occident Musulman et de la Méditerranée, Aix-en-Provence, ed. C.N.R.S., no. 
15-16/2, 1973, pp. 153-157. Mención del "Studium" fundado por Alfonso X en Murcia.

4370 - MAKKĪ, Mahmūd 'Alï: "Watā'iq tārijiyya Yađīida, 'an 'ass al-Murābī̄inn", [Documentos inéditos de la época almorávide], Revista del Instituto Égipcio de Estudios Islámicos en Madrid, Madrid, ed. Instituto Egipcio de Estudios Islámicos, ne. 7-8, 1959-1960, pp. 109-198. Documentación sobre revueltas en el Levante contra los almorávides.

4371 - MANZANO MARTINEZ, Jose; LOPEZ MARTINEZ, Jose D.; FERNANDEZ GONZALEZ, Francisco V.: "Una vivienda islámica en la calle pinares de la ciudad de Murcia", Miscelanea Medieval Murciana, Murcia, ed. Univ. de Murcia, no. 15, 1989, pp. 213-245.

4372 - MARGARIT TAYA, Antoni: "Valorant aquell ahir, mil anys després. La ratzia del 985 i les seves conseqüències en el repoblament del Penedès", Miscel Lania Penedesenca, no. 9, 1986, pp. 47-64.

4373 - MARIN PADILLA, Encarnación: "Los moros de Calatorao, lugar aragonés de señorio, en los siglos XIV y XV (I.)", Al-Qantara, Madrid, C.S.I.C., vol. $9 / 2,1988$, pp. 249-295. Su continuación en "Los moros de Calatorao, lugar aragonés de señorio, en los siglos XIV y XV (II)", Al-Qantara, Madrid, ed. C.S.I.C., vol. $10 / 11989$, pp. 175-214.

4374 - MARINETO SANCHEZ, P.: "Plaquitas y bote de marfil del taller de Cuenca", Miscelánea de Estudios Arabes y Hebraicos Granada, vol. XXXV, 1987.

4375 - MARTI MONTOLIU, Josep: "Castells, torres i nuclis de poblacio del regne de València a la Crónica de Jaume I", Estudis Castellonencs, Castello de la Plana, no. 3, 1986, pp. 381-407.

4376 - MARTIN CORRALES, Eloy: "Il commercio della Catalogna con il mondo islamico mediterraneo nel settecento", Islam. Storia e Civilta, Roma, Accademia della Cultura Islamica, año 7, fasc. $22,1988 / 1$, pp. 35-51.

4377 - MARTIN PASCUAL, Llucia: "Les fonts orientals de la Historia de Jacob Xalabin", Sharg Al-Andalus. Estudios Arabes, Alicante, ed. Univ. de Alicante, ne. 5, 1988, pp. 101-109.

4378 - MARTINEZ ALMIRA, Magdalena: "Bibliografía italiana de temática arabe (II)", Sharg Al-Andalus. Estudios Arabes, Alicante, no. 6, 1989, pp. 247-250.

4379 - MARTINEZ ALMIRA, Ma. Magdalena: "Celebraciones familiares en Al-Andalus", Sharg Al-Andalus. Estudios Arabes, Alicante, ed. Univ. de Alicante, ne. 5, 1988, pp. 193-200.

4380 - MARTINEZ RUIZ, Juan: "Contribución al estudio de la toponimia medieval de Castilla-La Mancha", I Congreso de Historla de Castilla-La Mancha. Musulmanes y Cristianos. La implantación del Feudalismo, Toledo, ed. Junta de Comunidades de Castilla-La Mancha, vol. V, 1988, pp. 117-125.

4381 - MARTINEZ SAMPEDRO, Ma. Desamparados: "Almeria en la Crónica latina de Jaime I", Andalucia entre Oriente y Occidente (1236-1492). Actas del V Coloquio de Historia Medieval de Andalucfa, Cordoba, Excma. Diputación de Cordoba, 1988, pp. 95-101.

4382 - MATEU BELLES, Joan F.: "Assuts 1 vores fluvials regades al País Valencia medieyal", Los Paisajes del Agua. Libro Jubilar dedicado al Prof. Antonio Lopez Gomez, Valencia, ed. Univ. de València / Univ. d'Alacant, 1989, pp. 165-185,

4383 - MELIS, Federigo: "La llana de l'Espanya mediterrània i de la Berberia Occidental en els segles XIV-XV", Valencia, un mercat medieval, editat per Antoni FURIo, Valéncia, ed. Diputacio Provincial de Valencia, 1985, pp. 61-80.

4384 - MENJOT, Denis: "La "periferización" del Mediterráneo Occidental en la Edad Media (Mediados del XI-mediados del XV)", Areas. Revista de 
Ciencias Sociales, Murcia, Editora Regional de Murcia, no. Extra 1986, pp. 42-53.

4385 - MENJOT, Denis: "Les minorités juives et musulmanes dans l'économie murcienne au bas Moyen Age", Minorites et marginaux en Espagne et dans le midi de la France, Paris, Editions du C.N.R.S., 1986, pp. 265-286.

4386 - MEYER, Egbert: "Ibn 'ArabI begegnet Ibn Ru'sd: variationen zum Thema Gotteserkenntnis", Zeltschrift für Geschichte der Arabisch-Islamischen Wissenschaften, $\mathrm{no}$. 3, 1986, pp. 280-334.

4387 - MIGUEL RODRIGUEZ, J. C. de: Los mudejares de la Corona de Castilla, Madrid, 1988, 82 pp.

4388 - MILLAN MARTINEZ, Juan Manuel: "Haro y los inícios de la repoblación en la Mancha conquense", I Congr. de Historia de Castilla-La Mancha. Musulmanes y Cristianos. La implantación del Feudalismo, Toledo, ed. Junta de Comunidades de Castilla-La Mancha, vol. V, 1988, pp. 153-161.

4389 - MIZAL, Jassim Abid (ed. trad. notas): AI-Idr̈isi. Los caminos de Al-Andalus en el siglo XII según "Uns al-Muhag wa-rawd al-furäy", Madrid, ed. C.S.I.C., 1989, 425 pp.

4390 - MOLINA LOPEZ, Emilio: "Aproximación al estudio de la Cartagena islámica", Historia de Cartagena Tomo V. Alta Edad Media (siglos VIII al XIII), Murcia, ed. Mediterráneo, 1986.

4391 - MOLINA LOPEZ, Emilio: "El "Kitāb Ihtis̄ar iqtibās al-anwār" de Ibn Al-Hiarrāt. El autor y la obra. Analisis de las noticias historicas, geograficas y biograficas sobre A1-Andalus", Quaderni di Studi Arabi, Venecia, no. 5-6, 1987-1988, pp. 540-560.

4392 - MOLINA LOPEZ, Emilio: "La obra histórica de Ibn Jätima", Al-Qantara, Madrid, ed. C.S.I.C., vol. X/1, 1989, pp. 151-174.

4393 - MOLINA MOLINA, Angel Luis: La vida cotidiana en la Murcia bajomedieval, Murcia, ed. Academia Alfonso X el Sabio, 1987, 228 pp.

4394 - MONCO GARCIA, Carlos: "La Alcazaba de Huete. Avance de las excavaciones realizadas en 1985", I Congr. de Historia de Castilla-La Mancha. Musulmanes y Cristianos. La implantación del Feudalismo, Toledo, ed. Junta de Comunidades de Castilla-La Mancha, vol. V, 1988, pp. 51-99.

4395 - MONTANER ERUTOS, Alberto: "Aproximación a una tipología de la literatura aljamiado-morisca aragonesa", Destierros Aragoneses. I. Judios y Moriscos (2a Parte: La expulsión de los Moriscos) Zaragoza ed. Institucion Fernando el Catolico 1988, pp. 313-326.

4396 - MORALES LEZCANO, Victor: "L'Impero ottomano nella letteratura spagnola. Dalle Turqueries all'Africanismo", Islâm. Storia e Civilta, Roma, Accademia della Cultura Islamica, año 7, fasc. 25, 1988/4, pp. 277-282.

4397 - MORENO FERNANDEZ, Francisco: "Ensayo de toponimia mozarabe del Común de la Mancha", Estudios sobre Alfonso VI y la Reconquista de Toledo. Actas II Con. Int. de Estudios Mozárabes, Toledo, ed. Instit. de Estudios Visigotico-Mozárabes, vol. I, 1987, pp. 295-313.

4398 - MOXO, Francisco de: "Nueva luz documental sobre la ascendencia musulmana de Benedicto XIII y la fecha de su nacimiento", Papeles Bilbilitanos. Actas del Segundo Encuentro de Estudios Bilbilitanos, Zaragoza, Centro de Est. Bilbilitanos / Inst. Fernando Catolico, vol. II, 1989, Pp. 243-250.

4399 - MUTGE I VIVES, Josefa: "Algunas noticias sobre las relaciones entre la corona Catalano-Aragonesa y el reino de Túnez de 1345 a 1360", Relaciones de la Peninsula Ibérica con el Mágreb (Siglos XIII-XVT). Actas del Coloquio, Madrid, ed. C.S.I.C. / I.H.A.C., 1988, pp. 131-161.

4400 - MUTGE I VIVES, Josefa: "L'ambaixada a Tunis de Guillem de Clariana i de Benet Blanques (1345)", Miscel lania de Textos Medievals. La frontera te- 
rrestre i Maritima amb l'Islam, Barcelona, ed. C.S.I.C., no. 4, 1988, pp. 163-220.

4401 - MU'NIS, H.ussain: "Les Almoravides. Esquisse historique", Revista del Instituto de Estudios Islámicos en Madrid, Madrid, ed. Instituto de Estudios Islámicos en Madrid, no. 14, 1967-1968, pp. 50-102.

4402 - MU'NIS, Hussain: Al-Qugrafiyya wa-1-Yugrafiyyin fí-1-Andalus, Madrid, ed. Instituto Egipcio de Estudios Islámicos, 1967, 723 pp.

$\boldsymbol{N} 4403$ - NAVARRO PALAZON, Julio: "Excavaciones arqueológicas en la ciudad de Murcia durante 1984", Excavaciones Y. Prospecciones Arqueologicas, Murcia, 1987, pp. 307-321.

4404 - NAVARRO PALAZON, Julio: "Hacia una sistematización de la cerámica esgrafiada", II Coloquio Internacional de la Ceramica Medieval en el Mediterráneo óccidental, Madrid, ed. Dirección General de Bellas Artes del Ministerio de Cultura, 1986, pp. 165-178.

4405 - NAVARRO PALAZON, Julio: "Siyasa: Una madina de la cora de Tudmir", Areas. Revista de Ciencias Sociales, Murcia, Editora Regional de Murcia, no. 5, 1985, pp. 170-189.

4406 - NAVARRO PALAZON, JULio; GARCIA AVILES, Alejandro: "Aproximación a la cultura material de Madinat Mursiyya", Murcia Musulmana, edición de F. J. FLORES ARROYUELO, Murcia, Ediciones Almudi, 1989, pp. 253-356.

4407 - NAVARRO POVEDA, Concepcion: Petrer Islamico, Petrer, ed. Ayuntamiento de Petrer / Inst. Juan Gil Albert, 1988, 35 pp.

4408 - NAVARRO POVEDA, Concepción: "Estudio del material cerámico islámico medieval de Petrer", Ayudas a la Investigacion. 1984-1985, Alicante, ed. Instituto de Estudios "Juan Gil Albert", vol. 2, 1985, pp. 81-109.

4409 - OLIVER ASIN, Jaime: "En torno a los origenes de Castilla: Su toponimia en relación con los árabes y los beréberes", Discurso lefdo para el Ingreso en la Real Academia de la Historia, Madrid, ed. Real Academia de la Historia, 1974, 73, pp.; y también en Al-Andalus, Madrid-Granada, ed. C.S.I.C., no. 49, 1974, pp. 319-391.

4410 - ORTEGA, Pascual: "De mudejares a moriscos: algunas reflexiones en torno a las relaciones sociales de producción y la conflictividad religiosa: el caso de la Ribera de l'Ebre (Tarragona)", Miscel lania de Textos Medievals. La frontera terrestre i Maritima amb l'Islam, Barcelona, ed. C.S.I.C., no. 4, 1988, pp.

4411 - Palomar liorente, Ma. Elisa: "Cerámica mudejar de Muel en el teatro romano de Zaragoza", Museo de Zaragoza. Boletín. Homenaje a Antonio Beltrán, Zaragoza, no. 4, 1985, pp. 185-192.

4412 - PALOMAR, Ma. Elisa; VILADES, José María: "Excavaciones en Zaragoza: Cerámica Bajomedieval en la Calle Mayor, no. 8", Boletı́n de la Asociación Española de Orientalistas, Madrid, vol. 24, 1988, pp. 393-411.

4413 - PANADERO MOYA, Miguel: "La formación del "núcleo histórico" en la ciudad de Albacete", Cultural Albacete, Albacete, ed. Diputación de Albacete, n. 6, junio 1984, pp. 3-14.

4414 - PARDOS GOMEZ, Santiago: "LOS moriscos: comienzo de una floreciente industra curtidora en el valle del rio Aranda", Papeles Bilbilitanos. Actas del Segundo Encuentro de Estudios Bilbilitanos, Zaragoza, Centro de Est. Bilbilitanos / Inst. Fernando Católico, vol. II, 1989, pp. 69-74.

4415 - PASCUAL, Llúcia: "La Takmila d'Ibn Al-Abbār com a font de la historia d'Onda i dels seus habitants", Miralcamp. Butllets d'Estudis Onders, Onda, no. 5, juny 1989, pp. 41-45.

4416 - PASTOR DE TOGNIERI, Reyna: "La conquista cristiana de Castilla la Nueva y el desarrollo de las estructuras feudales", I Congr. de Historia de Castilla-La Mancha. Musulmanes y Cristianos. La implantacion del Feudalismo, 
Toledo, ed. Junta de Comunidades de Castilla-La Mancha vol. V, 1988, pp. 127-136.

4417 - PATERNINA BONO, Ma. Jesús: "Relación de los moros y cristianos sujetos al impuesto del Morabatí en "lo loch de Ondara" en 1404", Sharg AI-Andalus. Estudios Arabes, Alicante, ed. Univ, de Alicante, no. 6, 1989, pp. 119-127.

4418 - PAVON MALDONADO, Basilio: "Miscelánea de arte hispanomusulmán. 6. En torno a los arcos islámicos de unos baños de Játiva", Boletín de la Asociación Española de Orientalistas, Madrid, ed. Asociación Española de Orientalistas, no. 15, 1979, pp. 204-206.

4419 - PAVON MALDONADO, Basilio: "Notas dispersas sobre arte y arqueología hispanomusulmanes", Anuario de Bstudios Medievales, Barcelona, ed. C.S.I.C., no. 18, 1988, pp. 77-96. Castillo de Alcalá la Real (Jaén), fortaliza de "Molina Vieja" en Molina de Aragón (Guadalajara).

4420 - PENYARROJA I TORREJON, Leopoldo: "El mossarap de València i la romanitat de l'Espanya islamica: Estat de l'investigacio", En torno al 750 aniversario. Antecedentes $y$ consecuencias de la conguista de Valencia, Valencia, ed. Consellería de Cultura Generalitat Valenciana, vol. I, 1989, pp. 199-225.

4421 - PEÑA GONZALVO, F. Javier: "Santa María de Maluenda. Evolución tipologica y constructiva", Papeles Bilbilitanos. Actas del Segundo Encuentro de Estudios Bilbilitanos, Zaragoza, ed. Centro de Est. Bilbilitanos / Inst. Fernando Católico, vol. I, 1989, pp. 311-316. Iglesia con antecedentes de mezquita; con un alminar de uso militar y religioso en tiempos islámicos.

4422 - PEREZ PRENDES, J. Manuel: "Aspectos jurídicos de la conquista: Las cartas pueblas", En torno al 750 aniversario. Antecedentes $y$ consecuencias de la conquista de Valencia, Valencia, ed. Consellería de Cultura Generalitat Valenciana, vol. I, 1989, pp. 335-343.

4423 - PERIS ALBENTOSA, Tomás: Privilegiados, marginados y campesinos, La estructura social de la propiedad en Alzira en 1580, Alzira, ed. Ayuntamiento de Alzira, 1988, 221 pp. Moriscos de Alcira como pequeños propietarios de tierras.

4424 - PEROPARDE MUNIESA, Angel; SOUTO LASALA, Juan A.: "Restos arqueologicos de época islámica en el subsuelo de la Seo del Salvador (Zaragoza). Campaña de 1980", Boletín de la Asociación Española de Orientalistas, Madrid, ed. Asociación Española de Orientalistas, vol. XXII, 1986, pp. 347-368.

4425 - PINILlA, Rafael: "Una obra andalusi de "Adab": La "Bahyät al-mâ̧älis" de 'Ibn 'Abd Al-Barr (s. XI JC)", Sharg Al-Andalus. Estudios Arabes, Alicante, ed. Univ. de Alicante, no. 6, 1989, pp. 83-101.

4426 - PLOU GASCON, Miguel: "Los moriscos de Letux y las consecuencias de su expulsion", Destierros Aragoneses. I. Judios y Moriscos (2a Parte: La expulsión de los Moriscos), Zaragoza, ed. Instit. Fernando el Cat6lico, 1988, pp. 291-302.

4427 - PLOU GASCON, Miquel: Historia de Letux, Zaragoza, ed. Ayuntamiento de Letux, 1989, 2a ed., 415 pp. Censo de Mudéjares (pp. 60-61), "Bautismo de los maros" (pp. 68-69), "Toda ella morisca" (pp. 81-82).

4428 - POCKLINGTON, Robert: "Ápostillas de hidronimia arábigo-murciana", Sharg Al-Andalus. Estudios Arabes, Alicante, ed. Univ. de Aicante, no. 5, 1988, Pp. 163-167.

4429 - POCKLINGTON, Robert: "La etimología del topónimo "Granada" ", Al-Qantara, Madrid, C.S.I.C., vol. 9/2, 1988, pp. 372-402. 27 topónimos peninsulares; entre ellos La Granada (Barcelona, Albacete), La Granadella (Tarragona, Alicante y Lleida). 
4430 - POCKLINGTON, Robert: "El origen del nombre de Murcia", Murcla Musulmana, edición de F. J. FLORES ARROYUELO, Murcia, Ediciones Almudi, 1989 , pp. $63-74$.

4431 - POCKLINGTON, Robert: "Nuevos datos sobre cinco puertas musulmanas $y$ una torre de la cerca medieval de Murcia", Murcia Musulmana, edición de F. J. FLORES ARROYUELO, Murcia, Ediciones Almudi, 1989, pp. 215-232.

4432 - POCKLINGTON, Robert: "Observaciones sobre el aprovechamiento del agua torrencial para la agricultura en Murcia y Lorca durante la época arabe", A venidas fluviales e inundaciones en la cuenca del Mediterráneo, ed. A. GIL OLCINA y A. MORALES GIL, Alicante, ed. Univ. de Alicante / C.A.M., 1989, pp. 395-401. Reeditado en Murcia Musulmana, ed. de F. J. FLORES ARROYUELO, Murcia, Ediciones Almudi, 1989, pp. 375-383.

4433 - POCKLINGTON, Robert: "Precisiones acerca de la fecha de fundacion de Murcia", Murcia Musulmana, edición de F. J. FLORES ARROYUELO, Murcia, Ediciones Almudi, 1989, pp. 55-61.

4434 - POLANCO ROIG, Lluís B.: "Sistemes de representacio grafica de mots àrabs en catalä", Sharq Al-Andalus. Estudios Arabes, Alicante, ed. Univ. de Alicante no. 51988 pp. 11-30.

4435 - PORTELLA COMAS, Jaume: "La colonitzacio feudal de Mallorca: els primers establiments de l'alqueria de Deiả (1232-1245)", Estudi General, Girona, ed. Col legi Universitari de Girona, no. 5-6, 1985-86, pp. 331-343.

4436 - POZO MARTINEz, Indalecio: "El despoblado islámico de "Villa Vieja", Calasparra (Murcia). Memoria Preliminar", Miscelanea Medieval Murciana, Murcia, ed. Univ. de Murcia, no. 15, 1989, pp. 185-212.

4437 - RAMIREZ COMPES, Jose Antonio: "La población morisca de Illueca en el Decreto de 1526", Papeles Billbilitanos. Actas del Primer Encuentro de Estudios Bilbilitanos, Zaragoza, ed. Centro de Est. Bilbilitanos / Inst. Fernando Católico, vol. II, 1979, pp. 243-259.

4438 - RAMIREZ SEGURA, Esperanza; IDAÑEZ SANCHEZ, Jose F.: "Cerámica islámica de la provincia de Albacete", I Congr. de Historia de Castilla-La Mancha. Musulmanes y Cristianos. La implantación del Feudalismo, Toledo, ed. Junta de Comunidades de Castilla-La Mancha, vol. V, 1988, pp. 73-83.

4439 - RESANO SANCHEz, Manuel: "Privilegios concedidos a Calatayud y su comarca por Jaime I el Conquistador", Papeles Bilbilitanos. Actas del Primer Encuentro de Estudios Bilbilitanos, Zaragoza, ed. Centro de Est. Bilbilitanos / Inst. Fernando Catolico, vol. II, 1979, pp. 267-275.

4440 - RIERA FRAU, Ma. Magdalena: "Ia onomástica andalusi de Madinat Mayurqa a través del "Llibre del Repartiment"", Estudios Onomástico-biograficos de Al-Andalus. II., editados por M. I. AVILA, Granada, ed. C.S.I.C., 1989, pp. 177-186.

4441 - RIERA I SANS, Jaume: "Les licències reials per predicar als jueus i als sarraïns (Segles XIII-XIV)", Calls, Tàrega, no. 2, 1987, pp. 113-143.

4442 - RIU, Manuel: L'Arqueologia medieval a Catalunya, Barcelona, ed. Els Llibres de la Frontera, 1989, 177 pp.

4443 - ROCA TRAVER, Francisco: "Precedentes y conquista de las tierras castellonenses", En torno al 750 aniversario. Antecedentes $y$ consecuencias de la cońquista de Valencia, Valencia, ed. Consellería de Cultura de la Generalitat Valenciana, vol. II, 1989, pp. 163-190.

4444 - RODRIGUEz CARREÑO, Angel M.: "Conquesta i feudalitzacio: el cas de Pollença, Mallorca (1298-1304)", Estudi General, no. 5-6, 1985-1986, pp. 371-387.

4445 - RODRIGUEz LLOPIS, Miguel: "Poblacion y fiscalidad en las comunidades mudéjares del reino de Murcia (siglo XV)", III Simposio Internacional de Mudejarismo, Teruel, 1986, pp. 39-53. 
4446 - RODRIGUEZ LLOPIS, Miguel: "Repoblación y organización social del espacio de los señorios santiaguistas de Murcia (1235-1350)", Mvrgetana Murcia, ne. 70, 1986, pp. 5-34.

4447 - RODRIGUEZ LORENTE, Juan Jose: "The last moslem gold coinage of Murcia: problems of medieval coinage in the Iberian Area", Sociedad Numismatica Avilesina y el Instituto de Sintra, Aviles, 1986-1987.

4448 - RODRIGUEZ LORENTE, Juan Jose (colaborador), Prontuario de la Moneda Arábigo-Española, Madrid, ed. J. Vico Monteoliva, 1982, 78 pp.

4449 - RODRIGUEZ MOLINA, Jaimez "El puerto del Muradal. Permeabilidad entre Castilla-La Mancha y Andalucia", I Congrr. de Historia de Castilla-La Mancha. Musulmanes y Cristianos. La implantación del Feudalismo, Toledo, ed. Junta de Comunidades de Castilla-La Mancha, vol. V, 1988, pp. 137-144. Enclave de sierra Morena, puerta entre Castilla y Andalucla.

4450 - ROSENTHAL, F. : "bn "Arabi between "Philosophy" and "Misticism", Oriens, Leiden, ne. 31, 1988, pp. 1-36,

4451 - ROSSELLO BORDOY, Guillem: "Notes sobre la conquesta de Mallorca (1229-1232). El testimoni dels vençuts", Mayurga. Homenatge a Alvaro Santamaria, Palma de Mallorca, no. 22, vol. II, 1989, pp. 541-549.

4452 - ROSSELLO BORDOY, Guillermo: "NuevOs epigrafes espontáneos en tinajas árabes menorquinas", Homenaje a Samuel de los Santos, Albacete, ed. Instituto de Estudios Albacetenes, 1989, pp. 235-242.

4453 - ROSSELLO BORDOY, Gullem: "Sharg Al-Andalus i la investigacio arqueologica: estat de la quiestio", Estudi General. La formacio i espansio del Feudalisme Catala. Homenatge a Santiago Sobreques $i$ Vidal, Girona, ed. Col legi Universitari de Girona, no. 5-6, 1985-1986, Pp. 253-263.

4454 - ROSSELLO I VERGER, Vicenç M.: "Els molins d'aigua de l'horta de Valencia", Los Paisajes del Agua. Libro Jubilar dedicado al Prof. Antonio López Gomez, Valencia, ed. Univ. de Valencia / Univ. d'Alacant, 1989, pp. 317-345.

4455 - ROY ANDRES, Ursula: "La repoblación en el condado de Aranda", Destierros Aragoneses. I. Judios y Moriscos 12 Parte: La expulsion de los Moriscos), Zaragoza, ed. Instit. Fernando el Católico, 1988, pp. 255-260.

4456 - RUBIERA MATA, Ma. Jesús: Bibliografla de la literatura hispano-arabe, Alicante, ed. Universitat d'Alacant, 1989, 75 pp.

4457 - RUBIERA MATA, Ma. Jesús: "Cançonetes de tipus "Kharja” en la literatura catalana", Miscel Lania Joan Fuster. Estudis de Llengua $i$ Literatura, Barcelona, ed. Publicacions de l'Abadia de Montserrat, vol. I, 1989, pp. 1-8.

4458 - RUBIERA MATA, Ma. Jesús: "La cultura musulmana: pensament, llenguatge $i$ formes literaries (Aspectes de la poesia arabigo-valenciana: el paradis i el paradis perdut)", En torno al 750 aniversario. Antecedentes y consecuencias de la conquista de Valencia, Valencia, ed. Conselleria de Cultura Generalitat Valenciana, vol. I, 1989, pp. 96-106.

4459 - RUBIERA I MATA, Ma. Jesús: Introduccio a la Literatura Hispano-Arab, Alacant, ed. Universitat d'Alacant, $1990,117 \mathrm{pp}$.

4460 - RUBIERRA MATA, Ma. Jesús: "Nueva aproximación al estudio literario de las jarchäs andalusies", Sharq Al-Andalus. Estudios Arabes, Alicante, ed. Univ. de Alicante, no. 5, 1988, pp. 89-100.

4461 - RUBIERA, Marla Jesús: "Els toponims arabigo-catalans del Baix Segura (Alacant)", Sharg AI-Andalus. Estudios Arabes, Alicante, ed. Univ. de Alicante, no. 6, 1989, pp. 159-160.

4462 - RUBIO GARCIA, Luis: La Corona de Aragón en la reconquista de Murcia, Murcia, ed. Univ. de Murcia, 1989, 145 pp. 
4463 - RUIBAL, Amador: "El castillo de Albadalejo ¿Villar de casa paterna?, un enclave medieval de origen romano", I Congr. de Historia de Castilla-La Mancha. Musulmanes y Cristianos. La implantación del Feudalismo, Toledo, ed. Junta de Comunidades de Castilla-La Mancha, vol. V, 1988, pp. 287-296.

4464 - RUIZ DOMENEC, Jose Enrique: "Las cartas de Reverter, vizconde de Barcelona", Boletín de la Real Academia de Buenas Letras de Barcelona, Barcelona, ed. Real Academia de Buenas Letras, n9. 39, 1983-1984, pp. 93-118. Reverter Guislabert, vizconde de Barcelona, vive en Marruecos entre 1135-1139, sirviendo militarmente a su sultán.

4465 - RUZAFA GARCIA, Manuel: "La frontera de Valencia con Granada: La ruta terrestre (1680-1440)", Andalucfa entre Oriente y Occidente (1236-1492). Actas del V Coloquio de Historia Medieval de Andalucla, Cordoba, ed. Excma. Diputación de Cordoba, 1988, pp. 659-672.

4466 - RUZAFA GARCIA, Manuel: "Els origens d'una familia de mercaders mudejars en el segle XV: Çaat Ripoll (1381-1422)", Afers, Catarroja, ed. Afers, vol. 7, 1988-1989, pp. 169-188.

4467 - RUZAFA GARCIA, Manuel: "Los mudéjares valencianos y la conquista de Málaga", Bstudios sobre Malaga $y$ el Reino de Granada en el $V$ Centenario de la Conguista Málaga, ed. Diputación Provincial de Málaga, 1987, pp. 401-410.

4468 - RUZAFA GARCIA, Manuel: "Las relaciones economicas entre los mudéjares valencianos y el reino de Granada en el siglo XV", Cologuio de Historia Medieval andaluza. Relaciones exteriores del Reino de Granada, Almerla, Inst. de Estudios Almerienses, 1988, pp. 343-381.

54469 - SABRIA RIUS, Ma. Teresa: "Els arabismes de la llengua catalana a les comarques de Girona", Revista de Girona Girona, ne. 126, 1988, pp. 57-67.

4470 - SADIDD AN-NU'AYMI, 'Abd Al-Karim: Ibn Sida wa-ätäruhu wa guhüduhu, El Cairo, 1985.

4471 - SAINZ DE LA MAZA LASOLI, Regina: "Los mecedarios en la Corona de Aragon durante la segunda mitad del siglo XIV. Noticias y documentos", Miscel lania de Textos Medievals. La frontera terrestre i Marfima amb l'Islam, Barcelona, ed. C.S.I.C., no. 4, 1988, pp. 221-300. Dedicados a la redención de cautivos cristianos en tierras islamicas.

4472 - SALAS AUSENS, Jose Antonio: "La sociedad aragonesa a comienzos del siglo XVII", Destierros Aragoneses. I. Judios y Moriscos (2a Parte: La expulsion de los Moriscos), Zaragoza, ed. Institución Fernando el Católico, 1988, pp. 155-170.

4473 - SALEM, Sahar el Sayed Abdel Aziz: Los Banū Jațīb: una dinastra muladr en la época musulmana, Alejandria, ed. Mu'assasä el-Taqqafa el-Ğámíiya, 1988.

4474 - SALRACH, Josep M.: "Els origens de l'Ordre de la Merce i el rescat de captius. Les croades i l'exercici de la caritat a l'edat mitjana", Acta Historica et Archaeologica Mediaevalia, Barcelona, ed. Univ. de Barcelona n?. 9, 1988 , pp. $189-201$.

4475 - SANCHEZ ADELL, Jose: "Las cartas pueblas de Castellon", En torno al 750 anivefsario. Antecedentes $y$ consecuencias de la conguista de Valencia, Valencia, ed. Conselleria de Cultura Generalitat Valenciana, vol. II, 1989, pp. 191-206.

4476 - SANChez ALONSo, Fernando: "La cultura de la Murcia musulmana", Murcia Musulmana, edición de F. J. FLORES ARROYUELO, Murcia, Ediciones Almudi, 1989, pp. 357-372.

4477 - SANCHEZ FERRER, José: "Sobre las alfombras actuales de Lezuza y las antiguas de Alcaraz", Al-Basit, Albacete, ed. Inst. de Estudios Albacetenses, ne. 9, abril 1981, pp. 119-139. 
4478 - SANCHEZ GOMEZ, Jose Luis: "Panorama arqueologico de Socovos", Congreso de Historia de Albacete. 8-11 de diciembre de 1983. I. Arqueologia y Prehistoria, Albacete, ed. Inst. de Est. Albacetenses / C.S.I.C., vol. I, 1984, pp. 341-375. Castillo islámico y lápida árabe de 1132.

4479 - SANCHEZ MARTINEZ, Manuel: "Comercio nazarI y piratería catalano-aragonesa (1344-1345)", Relaciones de la Península Iberica con el Mágreb (Siglos XIII-XVT). Actas del Cologuio, Madrid, ed. C.S.I.C. / I.H.A.C., 1988, pp. 41-86. S. XIV

4480 - SANCHEZ MARTINEZ, Manuel: "Mallorquines y genoveses en Almería durante el primer tercio del siglo XIV: el proceso contra Jaume Manfré (1339)", Miscel lania de Textos Medievals. La frontera terrestre $i$ Maritima amb I'Islam Barcelona ed. C.S.I.C. n2. 41988 pp. 103-162. Comercio catalán con el reino nazarı y el Mágreb. Asociaciones comerciales entre cristianos y musulmanes.

4481 - SANChEZ MARTINEZ, Manuel: "Las relaciones de la Corona de Aragón con los Paises musulmanes en la epoca de Pedro el Ceremonioso", Pere el Cerimonios $i$ la seva Epoca, Barcelona, ed. C.S.I.C., 1989, pp. 77-97.

4482 - SANCHEZ MARTINEZ, Manuel: "En torno a la piratería nazari entre 1330 y 1337", Andalucla entre Oriente y Occidente (1236-1492). Actas del V Coloquio de Historia Medieval de Andalucia, Cordoba, ed. Diputación de Córdoba, 1988, pp. 431-461.

4483 - SANCHEZ, Pilar; SERRANO, Eliseo: "Moriscos, Inquisición y conflictividad antiseñorial: Calanda, 1569-1610", Destierros Aragoneses. I. Judfos y Moriscos (2e Parte: La expulsión de los Moriscos), Zaragoza, ed. Inst. Fernando el Católico, 1988, pp. 353-364.

4484 - SANMIGUEL MATEO, Agustín: "El posible emplazamiento del núcleo originario de Calatayud", Papeles Bilbilitanos. Actas del Segundo Encuentro de Estudios Bilbilitanos, Zaragoza, Centro de Est. Bilbilitanos/ Inst. Fernando Católico, vol. I, 1989, pp. 149-162.

4485 - SANMIGUEL MATEO, Agustín: "Un raro tema oriental antiguo en el Calatayud del siglo XVII", Papeles Bilbilitanos. Actas del Segundo Encuentro de Estudios Bilbilitanos, Zaragoza, ed. Centro de Est. Bilbilitanos / Inst. Fernando Católico, vol. I, 1989, pp. 291-310.

4486 - SANMIGUEL MATEO, Agustin: "Restos de un posible alminar en Villalba del Perejil", Papeles Bilbilitanos. Actas del Segundo Encuentro de Estudios Bilbilitanos, Zaragoza, Centro de Est. Bilbilitanos / Inst. Fernando Católico, vol. I, 1989, pp. 271-278.

4487 - SANMIGUEL MATEO, Agustin: "San Andrés de Calatayud: Una iglesia con estructura de mezquita", Papeles Bilbilitanos. Actas del Segundo Encuentro de Estudios Bilbilitanos, Zaragoza, Centro de Est. Bilbilitanos / Inst. Fernando Catolico, vol. I, 1989, pp. 279-290.

4488 - SANTAMARIA, Alvaro: "Repoblación y sociedad en el reino de Mallorca (1230-1343)", Espacio. Tiempo y Forma. Serie III. Historia Medieval. Homenaje al Prof. Eloy Benito Ruano, Madrid, ed. U.N.E.D., Serie III, vol. 1, 1989, pp. 525-540.

4489- SANTOS GALLEGO, Samuel de los; SANZ GAMO, Rubr: "Fuentes bibliograficas do arqueología albacetenses", Al-Basit, Albacete, ed. Inst. de Estudios Albacetenses, no. 9, abril 1981, pp. 179-204.

4490 - SANZ ARTIBUCILla, José Ma.: "Los baños moros de Tarazona", Al-Andalus, Madrid-Granada, ed. C.S.I.C., no. 4, 1944, pp. 219-226.

4491 - SARASA SANCHEZ, Esteban: "La memoria del agua: La economía hidrálica en el Valle Medio del Ebro iUn ejemplo de supervivencia o de nueva implantación ...?", Aragón en la Edad Media. VIII. Homenaje al Profesor Emerito Antorio Ubieto Arteta, Zaragoza, ed. Univ. de Zaragoza, no. 8, 1989, pp. $633-647$. 
BIBLIOGRAFIA SOBRE TEMAS... / Franco-Epalza

4492 - SARRIA ABADIA, F.; SERRANO R.; CALVO, R.; HERNANSANZ, A.; MIÑANA, Ma. L.: "La Iglesia de San Juan de Vallupié: un programa de salvación (posiblemente dirigida ala población morisca)", Destierros Aragoneses. I. Judros y Moriscos (2a Parte: La expulsión de los Moriscos), Zaragoza, ed. Institución Fernando el Católico, 1988, pp. 341-352.

4493 - SASTRE MOLL, Jaume: "Caballeros estipendiarios en Mallorca (1311-1343)", Mayarga, Palma de Mallorca, ed. Universitat de les Illes Balears, 1989. pp. 569-579. Conquista de la Malorca islamica, reparto de tierras entre los conquistadores y caballeros que las defienden.

4494 - SASTRE MOLL, Jaume: "Estancia y salida de musulmanes libres y esclavos durante el reinado de Sancho I y Felipe de Mallorca", Butllets de la Societat Argueologica Lul liana, Palma de Mallorca, ed. Societat Arqueológica Lul Liana, no. 44, 1988, pp. 125-170. Esclavos musulmanes en el primer tercio del siglo XIV.

4495 - SASTRE MOLL, Jaume: "La exportacion de sai y pez de Ibiza", Estudis d'Historia Econdmica, Palma de Mallorca, ed. Grup d'Estudis d'Historia Economica, ne. 20/2, 1989, pp. 49-71. Al Mágreb e Italia.

4496 - SCHIPPERS, A.: "Short poems in Andalusian literature. Reflexions on Ibn Hafäg poems about figs", Gli Arabi nella Storia. Atti del IIII Congresso dell'U.E.A.I. Quaderni di Studi Arabi, Venecia, no. 5-6, 1987-1988, pp. 708- 717.

4497 - SENAC, Philippe: "Note sur les Husün de Lérida", Melanges de la Casa de Velazquez, Madrid, ed. Casa de Velázquez, no. 24, 1988, pp. 53-70.

4498 - SENAC, Philippe; ESCO, Carlos: "Une forteresse de la Marche Superieure d'Al-Andalus, le hisn de Sen et Men (Province de Huesca)", Annales du Midi, t. 99 y t. 100, 1987-1988, pp. 17-33.

4499 - SERRANO MARTIN, Eliseo: "Los moriscos de Calanda y Foz Calanda: condición social y consecuencias de su expulsion", Destierros Aragoneses. I. Judios y Moriscos (2a Parte: La expulsion de los Moriscos), Zaragoza, ed. Inst. Fernando el Católico, 1988, pp. 365-375.

4500 - SESMA MUNOOZ, José Angel: El establecimiento de la Inquisición en Aragón Zaragoza, ed. Inst. Fernando el Católico, 1987, 255 pp.

4501 - SFORZA, G.: Mugahid e la sua scorreria contro la citta di Luni Nuovi Studi, Turin, 1917.

4502 - SEORZA, G.: "Mugahid e le sue imprese contro la Sardegna e Luni (10151016)". Giornale Lingustico di Archeologia, Storia e Letteratura, Génova, no. 20, 1983, pp. 134-156.

4503 - SLAUGHTER, John E.: "De nuevo sobre la batalla de Uclés", Anuario de Estudios Medievales, Barcelona, ed. C.S.I.C., no. 9, 1974-1979, pp. 393-404.

4504 - SOTO I COMPANY, Ricard: "Alguns casos de gestio "colonial" feudal a la Mallorca del segle XIII", Estudi General Girona ed. Col legi Universitani de Girona, no. 5-6, 1985-1986, pp. 345-369.

4505 - SOUTO LASALA, Juan Antonio: "Notas acerca de dos elementos islámicos en el conjunto fortificado de Calatayud", Papeles Bilbilitanos. Actas del Primer Encuentro de Estudios Bilbilitanos, Zaragoza, ed. Centro de Est. Bilbilitanos / Inst. Fernando Catolico, vol. I, 1979, pp. 279-291.

4506 - SOUTO LASALA, Juan Antonio: "Sobre la génesis de la Calatayud islamica", Aragón en la Edad Media. VIII. Homenaje al Profesor Emerito Antonio Ubieto Arteta, Zaragoza, ed. Univ. de Zaragoza, ne. 8, 1989, pp. 675-695.

4507 - SUGRANYES DE FRANCH, Ramon: "Les propostes de Ramon Llull "de modo convertendi infideles"", Studia Lulistica. Miscellanea in honorem Sebastiani Garclas Palau, Palma de Mallorca, ed. Maioricensis Schola Lullistica, 1989, pp. 93-100. 
T 4508 - TEIXIDOR DE OTTO, Ma. Jesús; DOMINGO PEREZ, Concepcio: "Les séquies i els traçats urbans a València", Los Paisajes del Agua Libro Jubilar dedicado al Profesor Antonio Lopez Gomez, Valencia, Univ. de Valencia / Univ. d'Alacant 1989 pp. 287-301.

4509 - TERES, Elias: "Al-Walaya", topónimo árabe", Al-Andalus, Madrid-Granada, ed. C.S.I.C., no. 33/2, 1968, pp. 291-309.

4510 - TERRASSE, Henri: "Caracteres géneraux des émirats espagnols du XIe.siẻcle", Revue de l'Occident Musulman et la Mediterrané Aix-en-Provence, no. 2, 1966/2, pp. 189-198.

4511 - TORREBLANCA LOPEZ, Agustín: "Una expedicion de Rodrigo Manrique contra la frontera de Granada (junio de 1435)", Homenaje al Profesor Juan Torres Fontes, Murcia, ed. Univ. de Murcia / Acad. Alfonso X el Sabio, vol. II, 1987, pp. 1673-1680.

4512 - TORRES BALBAS, Leopoldo: "La Via Augusta y el arrecife musulmán", Al-Andalus, Madrid-Granada, ed. C.S.I.C., no. 24, 1959, pp. 441-448.

4513 - TORRES FONTES, Juan: "Adalides granadinos en la frontera murciana Homenaje al Padre Tapia. Almerfa en la historia, Almeria, ed. Cajalmeria, 1988, PP. 257-267.

4514 - TORRES FONTES, Juan: "Los Baños de la Reina", Mvrgetana, Murcia, ed. Academia Alfonso X el Sabio, no.40, 1975, pp. 63-73.

4515 - TORRES FONTES, Juan: "Fortuna en los siglos XIII y XIV (Notas y documentos para su historia)", Mvrgetana Murcia, ed. Academia Alfonso X el Sabio, ne. 28, 1968, pp. 47-102.

4516 - TORRES FONTES, Juan: "Murcia Medieval. Testimonio documental", MVIgetana, Murcia, ed. Academia Alfonso X el Sabio, no. 52, 1978, pp. 77-95. Mudejares, almogavares, cautivos e inestabllidad fronteriza.

4517 - TORRES FONTES, Juan: "Murcia Medieval. Testimonio documental. IV", Mvrgetana, Murcia, ed. Academia Alfonso X el Sabio, no. 55, 1979, pp. 93-117. Mudejares murcianos.

4518 - TORRES FONTES, Juan: "Murcia Medieval. Testimonio documental. VI. Ia frontera, sus hombres y sus instituciones", Mvrgetana, Murcia, ed. Academia Alfonso X el Sabio, no. 57, 1980, pp. 71-116.

4519 - TORRES FONTES, Juan: "Murcia Medieval. Testimonio documental. VII. Las obras de misericordia", Mvrgetana Murcia, ed. Academia Alfonso X el Sabio, no. 58, 1980, pp. 60-89. Rescates de murcianos capturados por granadinos.

4520 - TORRES FONTES, Juan: "Notas para la historia de la ganaderia murciana en la Edad Media", Miscelanea Medieval Murciana Murcia, ed. Univ. de Murcia, ne. 12, 1985, pp. 139-184.

4521 - TORRES FONTES, Juan: "Producción sedera murciana en la Edad Media", Mvrgetana, Murcia, ed. Academia Alfonso X el Sabio, no. 45, 1976, pp. 29-37.

4522 - TORRES FONTES, Juan: "El recinto urbano de Murcia musulmana Murcia Musulmana, edición de F. J. FLORES ARROYUELO Murcia Ediciones Almudí 1989 151-197

4523 - TORRES FONTES, Juan: "Relaciones castellano-aragonesas en la campaña del Estrecho", Andalucla entre Oriente $y$ Occidente (1236-1492). Actas del $V$ Cologuio de Historia Medieval de Andalucla, Cordoba, ed. Diputación de Córdoba, 1988, pp. 101-111.

4524 - TORRO, Josep: "Sobre ordenament feudal del territori i trasbasaments del poblament mudejar. La "Montanea Valencie" (1286-1291)", Afers, Catarroja, ed. Afers, vol. 7, 1988-1989, pp. 95-124.

4525 - TURK, Afif: "El reino de Zaragoza en el siglo XI de Cristo (V de la Hégira)", Revista del Instituto Egipcio de Estudios Islamicos en Madrid, 
Madrid, ed. Instituto Egipcio de Estudios Islámicos en Madrid, no. 17, 1972-1973, pp. 7-123; y en el ne. 18, 1974-1975, pp. 7-74.

U 4526 - UBIETO ARTETA, Antonio: "Los almorávides, el idioma romance y los valencianos", Temas Valencianos, Valencia, ne. 29, 1978, 24 pp.

4527 - UBIETO ARTETA, Antonio: Caffaro. De captione Almerie et Tortuose, Valencia, ed. Anubar, 1973, 52 pp.

4528 - UBIETO ARTETA, Antonio: BI "Cantar del Mo Cid" $y$ algunos problemas historicos, Valencia, 1973, $230 \mathrm{pp}$.

4529 - UBIETO ARTETA, Antonio: "La conquista y repoblación de Alcañiz", Teruel, Teruel, ne. 9, 1953, 18 pp.

4530 - UBIETO ARTETA, Antonio: "La conquista de Valencia en la mente de Jaime I", Saitabi, Valencia, no. 12, 1962, pp. 117-159.

4531 - UBIETO, Agustín: "Estado actual de los estudios sobre regadios aragoneses medievales", III Jornadas del estado actual de los Estudios sobre Aragón, Tarazona, 1980, pp. 885-892.

4532 - UBIETO ARTETA, Antonio: "Una tueva lectura del plano de Caesaraugusta romana", Homenaje al Prof. Garcla y Bellido, Madrid, 1988.

4533 - UBIETO ARTETA, Antonio: "El sitio de Huesca y la muerte de Sancho Ramirez", Argensola, Huesca, no. 4, 1953, pp. 61-69 y 139-148.

4534 - UNALI, Anna: Maxiners, pirates $i$ corsaris catalans a l'epoca medieval (trad, Ma. A. OLIVER, revis. Ma. T. FERRER), Barcelona, Edicions de la Magrana, 1986, $213 \mathrm{pp}$.

4535 - URVOY, Dominique: "Vues musulmans sur la personalité de Ramon Llull", Studia Lullistica. Miscellanea in Honorem Sebastiani Garcfas Palou, Palma de Mallorca, ed. Maioricentsis Schola Lullistica, 1989, pp. 115-118.

4536 - VALlVE, Joaquin: "Carthage et Carthagene au virIe. siècle", Actas del II Cologuio Hispano-Tunecino, Madrid, ed. I.H.A.C., 1973, pp. 7-12. CARTAGENA CARTAGO

4537 - VALIVE, Joaquín: "La emigración andalusi al Magreb en el siglo XIII (Despoblación y población de Al-Andalus)", Relaciones de la Península Iberica con el Mágreb (Siglos XIIT-XVT). Actas del Coloquio, Madrid, ed. C.S.I.C. / I.H.A.C., 1988, Pp. 87-129.

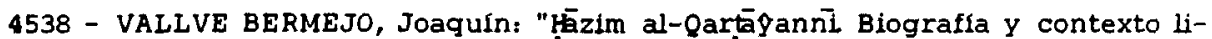
terario", Historia de Cartagena, Tomo V: Alta Edad Media (siglos VII al XIII), Murcia, ed. Mediterráneo, 1986.

4539 - VALLVE, Joaquin: Nuevas ideas sobre la Conquista árabe de España. Toponimia y Onomástica, Madrid, ed. Real Academia de la Historia, 1989, 205 pp. Reedición "Nuevas ideas sobre la conquista árabe de España. Toponimia y onomástica", Al-Qantara, Madrid, ed. C.S.I.C., vol. X/1, 1989, pp. $51-150$.

4540 - VARONA I GIL, Josep Eugeni: "Recull d'estudis histdrics onders", Centre d'Estudis Municipal d'Onda, Onda, ed. Ajuntament, no. 1, octubre 1988, pp. 175-189.

4541 - VENTURA CONEJERO, Agusti: "La Frontera del Xúquer", Papers de la Costerra, Alzira, ne. 1, 1981, pp. 31-48.

4542 - VERLIINDEN, Charles: "La esclavitud en la economia medieval de las Baleares, principalmente en Mallorca", Cuadernos de Historia de España, Buenos Aires, n9. 67-68, 1982, pp. 123-164.

4543 - VERNET, Juan: "Ambiente cultural de la Tortosa del siglo XII", Tamuda Rabat, n2. 5, 1957, pp. 330-339. Reedición en De 'Abd Al-Rahmấn I a Isabel II. Recopilacion de estudios dispersos ..., Barcelona, ed. C.S.I.C. / P.P.U., .1989 , pp. 461-470. 
4544 - VERNET, Juan: "Antroponimos árabes conservados en apellidos del Levante español", Oriens, no. 16, 1963, pp. 145-151. Reediciones en: Sharg Al-Andalus. Bstudios Arabes, Alicante, ed. Univ. de Alicante, no. 5, 1988, pp. 214-220, y en De 'Abd Al-Rahmán I a Isabel $I$. Recopilación de estudios dispersos ..., Barcelona, ed. C.S.I.C. / P.P.U., 1989, pp. 95-102.

4545 - VERNET, Juan: "Antroponimos de etimologla arabe en el Levante español. Ensayo metodologico", Revista del Instituto de Estudios Islámicos de Madrid, Madrid, ed. Inst. de Est. Islámicos, no. 11-12, 1963-64, pp. 141147. Reediciones en: , y en De 'Abd Al-Rahmân I a Isabel II. Recopilación de estudios dispersos ..., Barcelona, ed. C.S.I.C. / P.P.U., 1989, pp. 87-94.

4546 - VERNET, Juan: "Antroponimos musulmanes en los actuales partidos judiciales del Falset y Gandesa", Homenaje a Jaime Vicens $i$ Vives, Barcelona, vol. I, 1965, pp. 123-126. Reediciones en Sharg Al-Andalus. Estudios Arabes, Alicante, ed. Univ. de Alicante, no. 5, 1988, pp. 203-206, y en De 'Abd Al-Rahmán I a Isabel $\Pi$. Recopilación de estudios dispersos ..., Barcelona, ed. C.S.I.C. / P.P.U., 1989 pp. 103-108.

4547 - VERNET, Juan: De 'Abd Al-Rahman I a Isabel II. Recopilación de estudios dispersos ..., Barcelona, ed. C.S.I.C. /P.P.U., 1989. Recopilación de cerca de cincuenta artículos de Juan VERNET publicados en diversos

4548 - VERNET, JUan: "Dominacio islàmica", Historia de Barcelona Barcelona, vol. I, 1975, pp. 168-174. Reeditado De Abd Al-Rahmán I a Isabel II. Recopilacion de estudios dispersos ..., Barcelona, ed. C.S.I.C. / P.P.U., 1989, pp. 441-449.

4549 - VERNET, Joan: "La ciéncia abans de la conquesta", En torno al 750 aniversario. Antecedentes y consecuencias de la conquista de Valencia, Valencia, ed. Consell. de Cultura General. Valenciana, vol. II, 1989, pp. 227-237.

4550 - VERNET, Juan: "Josep M. Millàs Vallicrosa i la seva escola", Cinquanta anys de ciencia $i$ tecnica a Catalunya, Barcelona, 1987, pp. 193-203, reedición en De 'Abd Al-Rahman I a Isabel II. Recopilación de estudios dispersos .... Barcelona, ed. C.S.I.C. / P.P.U., 1989, pp. 535 y ss.

4551 - VERNET, Juan: "El nom de Catalunya", Historia de Catalunya, Barcelona, 1979, pp. 31-32. Reed. De 'Abd Al-Rahmán I a Isabel IT. Recopilación de estudios dispersos ..., Barcelona, ed. C.S.I.C. / P.P.U., 1989, pp. 457-459.

4552 - VERNET GINES, Juan: El rescate del arraez argell Bibi, prisionero en Mallorca, Tetuán Imprenta del Majzen, 1952, 14+42 pp.

4553 - VERNET, Juan: "Los reyes de Aragón iSon de ascendencia arabe?", Bages, Manresa, ne. 37, marzo 1956. reedición en De 'Abd Al-Rahmán I a Isabel Ir. Recopilación de estudios dispersos ..., Barcelona, ed. C.S.I.C. I P.P.U., 1989.

4554 - VERNET, Juan: "El valle del Ebro como nexo entre oriente y Occidente", De "Abd' Al-Rahmán I a Isabel II. Recopilación de estudios dispersos. Estudios sobre Historia de la Ciencia y cultura españolas. Ofrecida al autor por sus discipulos con ocasion de su LXV aniversario, Barcelona, ed. C.S.I.C. / P.P.U., 1989, pp. 259-296.

4555 - VERNET, Juan; LOPEZ LILLO, C.: "Un manuscrito morisco del Corán", Boletín de la Real Academia de Buenas Letras de Barcelona, Barcelona, ed. Real Ácademia de Buenas Letras, n?. 35, 1973-1974, pp. 185-255.

4556 - VIGUERA, Ma. Jesús: Aragón Musumán: la presencia del Islam en el Valle del Ebro, Zaragoza, Mira Editores, 198829 edición, 286 pp.

4557 - VIGUERA, Ma. Jesús: "Documentos mudéjares aragoneses", IIII Congreso de la Union Europea de Islamistas e Islamologos, publ. en Quaderni di Studi Arabi, no. 5-6, 1987-1988, pp. 786-790. 
4558 - VIGUERA, Ma. Jesús: "Las Cinco Villas en la Frontera Superior de Al-Andalus", II Jornadas de Bstudios de las Cinco Villas, Ejea de los Caballeros, 1988 pp. 11-32.

4559 - VILADES CASTILIO, José Maria: "Candiles árabes del teatro romano de Zaragoza", Museo de Zaragoza. Boletín. Homenaje a Antonio Beltrán, Zaragoza, no. 4, 1985, pp. 175-183.

4560 - VILAR, Juan Bautista: "Cartagena en las emigraciones españolas al Africa francesa", Awrag, Madrid, ed. I.C.M.A., vol. IX, 1988, pp. 125-149.

4561 - VILAR, Juan Bautista: Los españoles en la Argelia francesa (1830-1914), Prólogo de Jose Ma. JovER ZAMORA, Murciä, ed. C.S.I.C. / Univ. de Murcia, 1989, $435 \mathrm{pp}$.

4562 - VILAR, Juan Bautista: "Hallazgo de una biblioteca morisca en Potries (Gandía) en 1789", Sharg Al-Andalus. Bstudios Arabes, Alicante, ed. Univ. de Alicante, no. 5, 1988, pp. 147-152.

4563 - VILLALONGA DE CANTOS, P.: "Ia "Cónquista de Mallorca" en el cuadro de la historia. Su vision iconografica a través de la pintura del s. XIX", Mayurqa. Homenatge a Alvaro Santamaria, Palma de Mallorca, no. 22, vol. II, 1989.

4564 - VILLEGAS, Marcelino: "Narrativa arabe, otra interpretacion", Sharq Al-Andalus. Estudios Arabes, Alicante, ed. Univ. de Alicante, nQ. 5, 1988, pp. 111-128.

4565 - VILLEGAS, Marcelino: "Un texto de Al-"Aqqād (1889-1964) sobre Blasco Ibañez", Sharg Al-Andalus. Bstudios Arabes, Alicante, ed. Univ. de Alicante, no. 5, 1988, pp. 221-233.

4566 - VINCENT, Bernard: "Morisques et Chrétiens a Faura", Melanges de la Casa de Valazquez París, ed. Casa de Velázquez, no. 22, 1986, pp. 157-169. Junto a Morvedre/Sagunto.

4567 - VIRGILI, Antoni: "Conquesta, colonitzacio i feudalització de Tortosa (segle XII), segons el Cartulari de la Catedral", Estudi General. La formacio $i$ expansio del Feudalisme Catala. Homenatge a Santiago Sobreques $i$ Vidal, Girona, no. 5-6, 1985-1986, pp. 275-289.

W 4568 - WILLIAM BRODMAN, James: Ransoning Captives in Crusader Spain. The orders of Merced on the Christian Islamic Frontier, Philadelphia, University of Pennsylvania Press, 1986, XI + 196 pp.

4569 - YAHYA, Osman: Histoire et classification de l'oeuvre d'Ibn 'Arabi, Damasco, Institut Français de Damas, 1964, 698 pp.

4570 - YNDURAIN, Francisco: Los moriscos $y$ el teatro en Aragón. Auto de la destrucción de Troya y comedia pastoril Zaragoza, ed. Inst. Fernando el Católico del C.S.I.C., 1986, 175 pp.

Z 4571 - ZIMMERMANN, M.: "L'image du musulman et son utilisation en Catalogne du IXe. au XIIe. siècle", Minorités et marginaux en Espagne et dans le midi de la France, París, Editions du C.N.R.S., 1986, pp. 471-496.

\section{INDICES}

\section{INDICE DE FAMILIAS O PERSONAS}

Abü Zayd $\mathbf{4 1 6 5}$

Ahmad Al-Hanafi 4231

Armad Al-Gazzâl 4104

A.khila 4123

Al-'Aqqād 4565

\author{
Al-Azrag 4162,4166 \\ Al-Idrisi $4217,4265,4389$ \\ Al-Jarrát 4391 \\ Al-Qartấanni 4538 \\ Al-Rusat 4391 \\ Al-Zayyat 4187
}


Alfonso III el Liberal 4366

Alfonso X.el Sabio 4136, 4166, 4208, 4328

Alfonso el Batallador 4087

At-Tulaytuli 4190, 4191, 4193

At-Turtusi 4342

A veimpace 4352

Banū Gäniyya 4401

Banū Qäsim 4525

Banū-1-Jattāb 4473

Banū Hüd 4525

Benedicto XIII 4398

Blasco Ibáñez, Vicente 4565

Carlos I de España 4324

Cid, el (Rodrigo Diaz) 4528

Felipe II $\mathbf{4 3 3 1}$

Ibn 'Arabi 4111, 4202, 4300, 4351, $4386,4450,4569$,

Ibn 'Abd Al-Barr 4425

Ibn Al-Abbār $4230,4322,4415$

Ibn AI-Jatāb 4211

Ion Al-Sid 4353

Ibn Hisam Al-Qurtubi 4176

Ibn Hūd 4313

Ibn Jafāya 4496

Ibn Jātima 4392

Ibn Mardanis 4313

Ibn Paqūida 4352, 4354, 4356

Ibn Sab'in 4246

Ibn Sahl $\mathbf{4 2 9 5}$

Ibn Sida 4470

Ibrahim Taybili 4231

Istak II 4172

Ishak II, sultán de Túnez 4172

Ismail II 4134

Jacob Xalabin 4377

Jaume I 4137, 4162, 4163, 4166, 4244, $4360,4375,4381,4439$

Jaume II 4242

Juan II 4090

Mahoma (Muhammad) 4141

Millás Vallicorsa, J. M. 4550

Mujahid Salim Almanzor 4324

Muyahid 4501, 4502

Pere IV el Ceremoniós 4320, 4481

Raimon Llull 4200, 4211, 4507, 4535

Raimon Marti 4206

Ramón Berenguer IV 4335

Reverter Guislabert 4185, 4335, 4464

Rodrigo Manrique 4511

Sancho Ramfrez 4533

Sid Bono 4263

Witiza 4123,4199

Yàqüt 4157,4325

Zarhūn 4290

Zauzala 4088

ACEIFAS 4372

ADAB 4425

ADALIDES 4513

ADMINISTRACION 4230

AGRICULTURA ANDALUSI 4116, 4173, 4312,4432

AGRICULTURA MEDIEVAL 4328

AGUA 4139, 4144, 4168, 4169, 4209, $4216,4229,4262,4272,4285,4299$. $4382,4432,4454,4490,4491,4508$, 4517

AGUILAS 4276

ALBACETE 4271, 4305, 4333, 4413, 4438, 4489

ALBADALEJO $\mathbf{4 4 6 3}$

ALBARRACIN 4353

ALBOX 4089

ALCALA DE JUCAR 4265

ALCALA LA REAL 4419

ALCANIZ 4529

ALCARAZ 4350, 4438, 4477

ALCIRA 4207, 4251, 4298, 4336, 4423, 4496

ALFOMBRAS 4477

ALICANTE $4103,4108,4110,4148,4244$, $4245,4321,4328$

ALIMENTACION 4116,4288

ALMERIA 4209, 4381, 4391, 4392, 4480, 4527

ALMODOVAR 4293

ALMOGAVARES 4516,4519

ALMOHADES $4176,4313,4503$

ALMONACID DE LA SIERRA 4100

ALMORAVIDES $4087,4370,4401,4526$

ALQUERIAS 4207, 4284, 4312, 4435, 4436

ALZIRA 4255

ANTROPONIMIA ARABE 4544-4547

APEOS, LIBROS DE 4089

ARAGON (REINO, CORONA) 4088, 4135, $4136,4150,4151,4172,4197,4203$, $4221,4243,4248,4262,4345,4346$, $4357,4373,4395,4414,4471,4472$, $4500,4523,4531,4553,4556,4557$, 4570

ARANDA, VALLE 4455,4414

ARGEL 4552

ARGELIA 4560,4561

ARQUEOLOGIA ANDALUSI 4096, 4107, $4109,4110,4117,4121,4126,4127$, $4132,4133,4138,4146,4179,4203$, $4209,4213,4227,4236,4238,4240$, $4251,4255,4260,4271,4276,4287$, $4293,4302,4316,4317,4319,4321$, $4333,4336,4337,4344,4348,4357$, $4358,4362,4363,4371,4374,4394$, 
$4403-4406,4408,4412,4418$, 4419, 4424, 4431, 4436, 4438, $4447,4452,4453,4463,4478$, 4484, 4489, 4505, 4506, 4532, 4559

ARQUEOLOGIA MEDIEVAL 4442

ARQUITECTURA ANDALUSI 4121, 4138, $4145,4241,4287,4406,4453$

ARQUITECTURA MUDEJAR 4102, 4150

ARRAECES 4552

ARTE ANDALUSI 4121, 4236, 4287, $4418,4419,4485,4486$

ARTE MUDEJAR 4102, 4147, 4150, $4151,4152-4155,4171,4241,4334$, 4364,4419

ARTESANIA TEXTIL 4291, 4477, 4521

ARTESANIA TINTORERA 4477

ASTROLOGIA 4161

ASTRONOMIA 4161, 4549

ATALAYA, CASTILLO DE $\mathbf{4 2 3 5}$

BALEARES 4234, 4481, 4501, 4502, 4542

BANDOLERISMO 4516

BANOS 4109, 4144, 4145, 4149, 4225, $4227,4237,4260,4302,4336,4337$, $4344,4348,4406,4418,4490,4514$

BARBASTRO 4525

BARCELONA 4129, 4130, 4185, 4335, 4481,4548

BENIFASSA 4307

BENIFATO 4263

BEREBERES 4213, 4310, 4401

BIBLIOGRAFIAS 4141, 4143, 4208, $4222,4235,4267,4378,4456,4489$

BIBLIOTECAS 4195

BIOGRAFIAS 4105

BOCAIRENT 4266

BORRIOL 4165

CABACES 4115

CADIES 4175

CALAHORRA 4505

CALANDA 4483, 4499

CALASPARRA 4436

CALATAYUD 4087, 4212, 4240, 4241, $4319,4325,4357,4362-4364,4439$, $4484,4485-4487,4506,4525$

CALATORAO 4339,4373

CALIFATO 4125

CALIS 4291

CAMINOS 4108, 4178, 4273, 4279, 4389, $4449,4485,4512$

CAMP D'ALACANT 4242

CAMPO DE CARINENA 4101

CANADAS 4520

CARTAGENA 4104,4273, 4275, 4295, $4390,4536,4538,4560$

CARTAGO 4536

CARTAS PUEBLAS 4284, 4294, 4422, 4475

CASAS 4371,4406
CASTELLOLOGIA 4107, 4110, 4132, $4133,4238,4273,4276,4319,4357$, $4358,4362,4363,4394,4442,4463$, $4478,4497,4498,4505$

CASTELLON DE LA PLANA 4103, 4473, 4475

CASTILLA (REINO, CORONA, CASTILLA LA VIEJA) $4136,4387,4409,4523$

CATALUNA (CATALUNYA) 4134, 4185, $4199,4210,4248,4262,4316,4330$, $4365,4376,4399,4400,4442,4479$, $4534,4548,4451,4554,4571$

CAUDETE 4148

CAUTIVIDAD 4130, 4214, 4274, 4292, $4343,4471,4474,4479,4494,4513$, $4516,4518,4519,4552$

CERAMOLOGIA 4097, 4107, 4146, 4198 , $4213,4236,4251,4321,4333,4394$, $4404,4406-4408,4411,4412,4438$, $4442,4452,4453,4478,4559$

CERDENAA 4501

CHUEAS 4116

CIENCIAS ANDALUSIES 4122, 4156 , $4547,4549,4550$

CIEZA 4405, 4406

COMERCIO 4125, 4129, 4130, 4188, 4228, $4298,4318,4326,4343,4359,4367$, $4376,4383,4384,4399,4468$, $4479-4481,4495,4523$

CONQUISTA CRISTIANA 4087, 4095, $4108,4124,4137,4163,4170,4198$, $4242,4244,4245,4250,4254,4256$, $4259,4269,4284,4294,4312,4341$, $4350,4372,4388,4416,4422,4439$, $4443,4444,4451,4462,4467,4475$, $4488,4493,4526,4529,4530,4533$, $4541,4563,4567$

CONQUISTA ISLAMICA 4123, 4196, 4199, 4539

CONVERSIONES (CONVERSOS) 4306, 4441,4507

CORAN 4141

CORDOBA 4419

CORSARISMO 4214, 4343, 4479, 4482, 4534

CREVILLENTE 4126,4297

CRONICAS CATALANAS 4375

CRONICAS LATINAS 4381

CUENCA 4095, 4183, 4374, 4383, 4388

CUEVAS DE ALMANZORA 4261

CULTURA ANDALUSI 4195, 4282, 4345 , $4458,4476,4543,4549$

CURTIDORES 4414

DAROCA 4525

DEIA 4435

DENIA $4107,4337,4425,4501,4502$

DERECHO MUSULMAN $4113,4120,4175$, $4176,4190,4193,4342$

DESPOBLADOS 4240,4436

DOCUMENTACION 
ARABE $4161,4166,4190,4330,4339$, $4340,4370,4557$

MEDIEVAL CASTELLANA 4090, 4514, 4519

MEDIEVAL CATALANA 4092, 4120, 4243

MEDIEVAL 4089, 4164, 4350, 4361, $4388,4515,4516,4518,4527,4567$

EBRO (RIO, VAILE) 4157, 4410, 4491, 4554, 4556

ECONONOMIA ANDALUSI 4194

EDUCACION 4492

EJEA DE LOS CABALLEROS 4558

ELCHE 4145

ELDA 4148

EMIGRACION 4560,4561

EMIRATO 4091,4125

EPIGRAFIA ARABE 4117, 4287, 4305, 4452,4453

EPISTEMOLOGIA 4127

ERUSTES 4419

ESCLAVITUD 4164, 4165, 4494, 4542, 4568

ESPADAN, SIERRA 4168, 4249

ESTRECHO DE GIBRALTAR 4523

ETIMOLOGIAS 4112,4113, 4115, 4201, $4228,4469,4551$

EVANGELIZACION $\mathbf{4 4 9 2}$

FALSET 4546

FAURA 4566

FEUDALISMO 4124, 4127, 4270, 4314, $4416,4435,4444,4504,4567$

FIESTAS 4379

FILOSOFIA ISLAMICA $4345,4352-4354$, 4356,4450

FORTUNA 4515

FOZ CALANDA 4499

FRAGA 4171

FRONTERAS 4091, 4095, 4136, 4230, $4252,4274,4278,4281,4384,4388$, $4465,4474,4511,4513,4516,4518$, $4519,4541,4558,4568$

FUENTES ARABES 4157, 4217, 4265, $4322,4325,4389,4391,4392,4415$

FUEROS 4439

GALLINERA, VALL DE 4118, 4119

GANADERIA 4309, 4383,4328, 4520

GANDESA 4546

GANDIA 4562

GENOVA 4480

GEOGRAFIA $\$ 4187,4217,4402$

GERONA $\mathbf{4 4 6 9}$

GRAFFITI $\$ 452$

GRANADA $4106,4130,4134,4135,4263$, $4274,4278,4326,4327,4329,4359$, $4429,4465,4468,4479,4482,4511$, 4513,4518

GRANJA DE SOMED 4325

GUADALEST 4263

GUARDAMAR DEL SEGURA 4110
GUERRA DE LOS DOS PEDROS 4135, 4320

HARO 4388

HELLIN 4271, 4303, 4305

HIDRONIMIA ARABE 4428

HISTORIA ANDALUSI 4110, 4114, 4123, $4156,4196,4223,4224,4230,4234$, $4313,4347,4372,4390,4401,4402$, $4525,4536,4539,4547,4548,4556$

HISTORIA MEDIEVAL 4528, 4553

HISTORIOGRAFIA 4141, 4143, 4177, $4222,4223,4234,4314,4329,4550$

HUESCA 4128, 4218, 4498, 4533

HUETE 4394

ILLUECA 4334, 4437

IMPERIO OTOMANO 4396

IMPUESTOS 4092, 4417, 4445

INMIGRACION $\mathbf{4 3 6 5}$

INQUISICION 4183, 4184, 4306, 4483, 4500

INUNDACIONES $4179,4264,4272,4432$

ISLAMOLOGIA 4098, 4109, 4141, 4231, $4323,4348,4355,4379$

ITINERARIOS 4178, 4217, 4279, 4389, $4503,4512,4520,4554$

JARCHAS 4204, 4457, 4460

JATIVA $4230,4418,4425,4541$

JAVEA 4117

JILOCA (RIO, VALLE) 4358

JOROUERA 4438

JUCAR (RIO, VALLE) 4265, 4541

JUECES 4175

LA MANCHA (CASTILIA LA NUEVA) $4380,4397,4409,4416,4449$

IA RAPITA (ALT PENEDES) 4308

LENGUA ARABE $4200,4219,4434,4470$

LENGUA CATALANA 4092, 4201, 4219, $4250,4434,4469$

LENGUA ROMANCE 4526

LERIDA 4220, 4497

LETUX 4301, 4426

LEZUZA 4477

LITERATURA ALJAMIADA 4189, 4192, $4231,4233,4395,4555,4562$

ANDALUSI 4111, 4156, 4204, 4205, $4211,4246,4295,4377,4425$, $4456-4460,4470,4496,4538$

ARABE $, 4205,4290,4564$

CASTELLANA 4233,4570

CATALANA $4200,4211,4457$

CONTEMPORANEA ARABE 4565

LORCA 4274,4432

LUNI 4501, 4502

MADRASAS 4369

MAESTRAZGO 4315

MAGREB $4129,4140,4160,4185,4281$, $4318,4335,4376,4383,4464,4481$, 4495,4560

MALAGA 4467

MALIKISMO 4176, 4342 
MALLORCA 4188, 4283, 4367, 4370, $4435,4440,4444,4451,4480,4482$, $4488,4493-4495,4501,4502,4504$, 4552,4563

MALUENDA 4421

MANUSCRITOS 4191, 4193, 4195, 4361, 4555

MARCA SUPERIOR 4091, 4156, 4238, 4558

MATEMATICAS 4549

MEDICINA MEDIEVAL 4332, 4547, 4549

MENORCA 4366,4452

MERCENARIOS 4185, 4335, 4464

MESTA 4520

METODOLOGIA 4127,4545

MEZQUITAS 4171, 4240, 4421, 4486, 4487

MISTICA ISLAMICA 4111, 4202, 4246, $4263,4300,4351,4352,4386,4450$, 4569

MOLINA DE ARAGON 4419

MOLINOS 4127, 4442, 4454, 4491

MOMPICHEL 4438

MONOVAR 4148

MORELLA 4307

MORISCOS 4088, 4103, 4131, 4142, $4143,4181-4184,4189-4192,4221$, $4231,4233,4249,4257,4272,4292$, $4323,4324,4331,4395,4410,4414$, $4423,4427,4437,4472,4483,4492$, $4499,4500,4555,4562,4566,4570$

ALJAMAS 4301

EXPUISION 4093, 4100,4101, 4140, $4148,4197,4283,4298,4426,4455$, $4472,4483,4499$

MOROS Y CRISTIANOS 4182

MOZARABES $4186,4218,4420$

MUDEJARES 4090, 4092, 4096, 4097, $4102,4120,4128,4147,4162-4165$, $4167,4170,4171,4174,4193,4212$, $4221,4241,4243,4248,4252,4254$, $4263,4268,4282,4284-4286,4297$, $4315,4320,4327,4328,4330,4346$, $4359,4361,4364,4373,4385,4387$, $4393,4410,4411,4417,4422,4427$, $4441,4446,4466,4467,4468,4504$, $4516-4521,4524,4557,4571$

ALJAMAS 4339,4445

REVUELTA MUDEJAR 4106, 4166, 4515

MUEL 4411 :

MULADIES 4091, 4473

MUNDO (RIO, VALIE) 4428

MURADAL, PUERTO 4449

MURCIA 4090, 4099, 4136, 4138, 4173, $4176,4177,4178,4180,4202,4230$, $4243,4246,4257,4258,4260,4261$, $4273,4274,4277-4279,4295,4303$, $4351,4369,4371,4385,4393$, $4403-4406,4428,4430-4433,4445$,
$4447,4462,4473,4476,4482,4511$, $4513-4522,4569$

MUSICA 4289

MUWAXAJAS 4204, 4460

NARRATIVA ARABE 4564

NOVELDA 4148,4340

NUMISMATICA ANDALUSI 4123, 4125 , $4127,4199,4210,4260,4261,4275$, $4296,4447,4448,4453$

OLESA DE BONESVALLS 4349

ONDA $4092,4121,4284,4285,4287$ 4294,4540

ONDARA 4417

ONOMASTICA ARABE 4105, 4118, 4338, 4440

ONTINYENT 4266

ORDEN DE LA MERCED $4471,4474,4568$

ORDEN DE MONTESA 4315

ORDEN DE SANTIAGO $\mathbf{4 4 4 6}$

ORDEN DEL HOSPITAL 4092

ORDENES MILITARES $4315,4446,4471$, 4474,4568

ORIHUELA $4148,4216,4252,4253,4327$, 4391,4461

OSMA 4174

PATERNA 4096, 4097

PEREGRINACION 4368

PERPUXTENT 4133

PERTUSA 4301

PETRER 4139,4407, 4408

PEZ 4495

PINA DE EBRO 4153

PIRACES 4238

PIRATERIA 4292,4479, 4482, 4534

PIRINEOS 4196,4217

PLAGAS 4370

POESIA ANDALUSI $4111,4496,4538$

POLEMICAS $4200,4206,4507,4535$

POLLENSA 4444

PORTUS 4428

PRIEGO 4478

PRIORAT 4115

PUSA 4407

QANAT(S) 4299, 4349

RABITAS $4158,4215,4308$

RAFALES 4309, 4312, 4461

REDENCION 4214

REDOVAN $\mathbf{4 4 6 1}$

RELACIONES 4098, 4129, 4134, 4135 $4172,4185,4200,4211,4232,4278$, $4281,4329,4335,4359,4365,4384$, 4396

DIPLOMATICAS $4172,4320,4361$, $4370,4399,4400,4523$

ECONOMICAS 4125

RELIGION ISLAMICA 4098, 4323

RELOJES 4122

RENEGADOS 4306,4518

REPARTIMENTO ISLAMICO 4199 


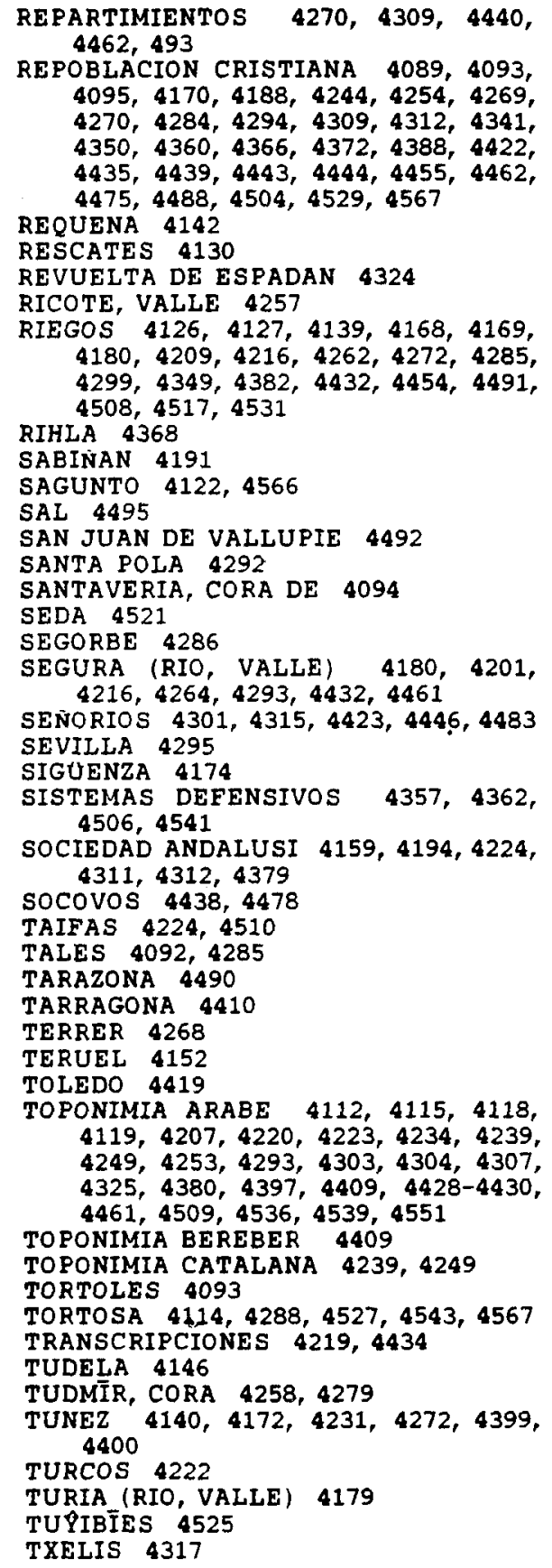

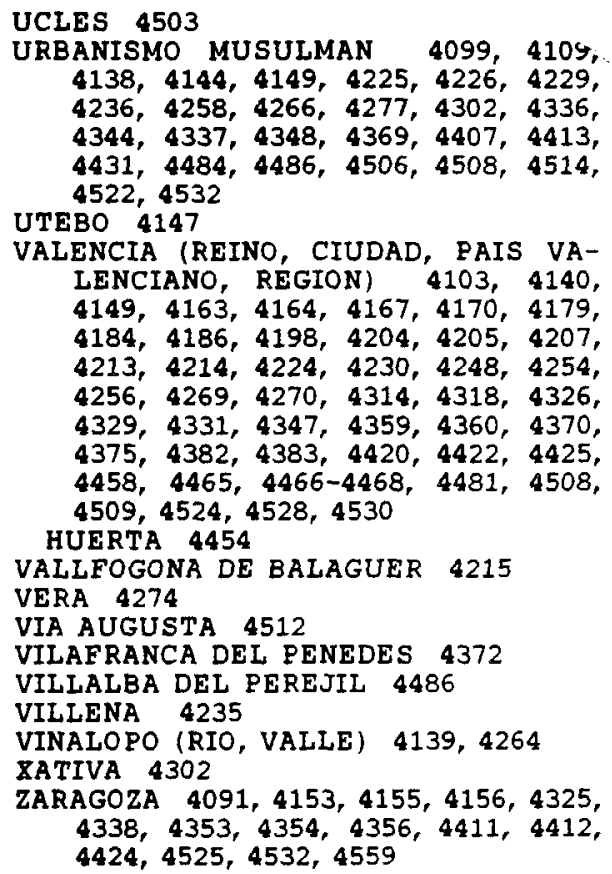

